NBSIR 78-1509

\title{
An Algorithm and Basic Computer Program for Calculating Simple Coal Gasification Equilibria
}

William S. Horton

Chemical Stability and Corrosion Division Center for Materials Science National Measurement Laboratory National Bureau of Standards

Washington, D.C. 20234

August 1978

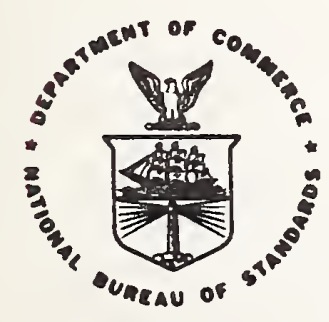

U.S. DEPARTMENT OF COMMERCE NATIONAL BUREAU OF STANDARDS 
NBSIR 78-1509

in 0
AN ALGORITHM AND BASIC COMPUTER PROGRAM FOR CALCULATING SIMPLE COAL GASIFICATION EQUILIBRIA

William S. Horton

Chemical Stability and Corrosion Division Center for Materials Science National Measurement Laboratory

National Bureau of Standards

Washisngton, D.C. 20234

August 1978

U.S. DEPARTMENT OF COMMERCE, Juanita M. Kreps, Secretary

Dr. Sidney Harman, Under Secretary

Jordan J. Baruch. Assistant Secretary for Science and Technology

NATIONAL BUREAU OF STANDARDS. Ernest Ambler, Director 



\section{TABLE OF CONTENTS}

Page

Introduction

Thermodynamic Basis and Assumptions 4

Thermodynamic and Mathematical Treatment 7

$\begin{array}{ll}\text { General Statement of the Algorithm } & 17\end{array}$

Application to a Simplified Coal Gasification System 25

Thermodynamic Data 30

Detailed Algorithm 32

Discussion of the Listing 45

$\begin{array}{ll}\text { Information for Using the Program } & 47\end{array}$

The Phase Rule $\quad 50$

Examples $\quad 55$

$\begin{array}{ll}\text { Appendices } & 63\end{array}$

1. Symbols - Text 63

2. Symbols - Listing 65

3. Listing 67

$\begin{array}{ll}\text { References } & 75\end{array}$ 

An Algorithm and BASIC Computer Program for Calculating Simple Coal Gasification Equilibria

\author{
William S. Horton \\ Center for Materials Science \\ National Bureau of Standards \\ Washington, DC 20234
}

\title{
INTRODUCTION
}

Designing plants for the gasification of coal is being aided by testing materials expected to be capable of withstanding the required conditions. A variety of physical and chemical tests are performed under these possible conditions and in the same gaseous environments. Generally, however, to fully understand the observed effects, tests are made in a variety of environments related to those of the gasification plants and at a variety of conditions of temperature and pressure. The gas mixtures used as the environments are generally not at chemical equilibrium, and depending upon the conditions and the possible presence of catalyzing substances, chemical reactions will take place [2] at some unpredictable speed. The tester is concerned about the true nature of the environment, but this can only be found by carefully arranged chemical analyses. On the other hand it is of value to know the maximum change that can occur during the test. This can be determined if the equilibrium composition for the mixture can be calculated. 
This report is concerned with a simple procedure for calculating the equilibrium composition of such testing mixtures. The aims in devising this procedure were to provide an interactive computer program that was easy to use, not inherently complex, that exploited the relative simplicity of the BASIC programming language, and was confined to the coal gasification problem alone. Such a program would be usable by nonprogrammers, who merely need to sign on an interactive timesharing terminal and type answers to a few questions about the testing conditions. There are batch programs already available for solving simultaneous chemical equilibria, e.g., CEC71 [8], however these have many disadvantages for the problem at hand. They are often complex, handle many more problems than are needed, require extensive storage, have excessive print-out, and require some learning prior to use. There is an interesting algorithm [14] with a computer program written in ALGOL, which treats multiphase chemical equilibria involved in coal combustion. This includes formation of slag.

The development of a program fulfilling these aims is presented here. Included are the mathematical and chemical thermodynamic treatment. Instructions for use and a listing are provided. Also included are some results obtained using the program which illustrate the use of the phase rule to predict the potential condensation of solid carbon during a materials test under coal gasification related conditions.

The program, called COLGAS, is capable of calculating equilibrium gas compositions containing $\mathrm{CH}_{4}, \mathrm{CO}, \mathrm{CO}_{2}, \mathrm{H}_{2}$, and $\mathrm{H}_{2} \mathrm{O}$ as well as the quantity of solid carbon and/or liquid water when these are present. 
Constant temperature is assumed, but the operator may choose to hold either pressure or volume constant.

The exposition may appear more detailed than is warranted for the simplicity of the problem to which the development is applied. The author found this to be helpful in seeing the relationship of the parts and the exact nature of the assumptions used. The detail has been retained in the report with the hope that some readers may benefit thereby.

Wherever possible the recommendations of The International Union of Pure and Applied Chemistry (IUPAC) for physicochemical symbols and units [3] have been followed. This includes the SI units. However, the atmosphere, liter, and degree Celsius have been made usable. The SI units used are the megapascal (MPa) and the kelvin (K). Because of the desire to keep symbolism the same in the text and in the computer program wherever possible, occasionally the IUPAC symbol has not been used. For example, $k$ is used for equilibrium constant rather than $k$. 


\section{THERMODYNAMIC BASIS AND ASSUMPTIONS}

The literature dealing with calculation of chemical equilibrium compositions is abundant, and most of it up to 1970 is given by van Zeggeren and Storey [9]. Other useful reviews are by Zeleznik and Gordon [13] and Klein [18]. The two known approaches depend upon either solving simultaneous equilibrium constant equations or minimizing the Gibbs energy of the system (for a constant pressure problem). Both include the constraints for conserving the chemical elements. The first of these methods is rather old, but Brinkley [10] is credited with developing a generalized scheme for a systematic treatment using equilibrium constants. This procedure is amenable to the use of computers. The first reference to minimizing the Gibbs energy as a route to solving simultaneous chemical equilibria was probably by White, Johnson, and Dantzig [11]. In principal, however, these two approaches are equivalent. This becomes obvious if minimization is effected by setting the partial derivatives with respect to the constituents equal to zero. The result is a set of equations involving the logarithms of the species concentrations. If logarithms are taken of the Brinkley equilibrium constant equations a set of similar equations is obtained. With a certain choice of "constituents" in the Brinkley sense, these sets of equations are identical. A real difference in the methods can occur if minimization is effected by other methods such as steepest descent or linear programming $[11]$.

Minimization of the Gibbs energy by use of the partial deriviatives has at least one advantage over the Brinkley method. There is no need 
to choose substances likely to be present in larger abundance than others and to treat these differently. All substances in the gas phase are treated alike and therefore the algorithm can be a bit less complex. Furthermore, the addition of a new substance is always done in the same way and does not lead to rewriting the equations already in the algorithm. Only new equations are added. For these reasons minimizing the Gibbs energy was the chosen method. Minimization is accomplished by the use of Lagrangian multipliers and setting the partial derivatives equal to zero followed by the Newton-Raphson method of solution. Minimization of the Helmholtz energy for constant volume problems leads to equations only slightly different from those for constant pressure and to minor additions to the program.

For the testing of coal gasification plant materials a reference environment has been chosen [12] and is shown in Table 1.

Table 1. Standard Gas Environment

\begin{tabular}{ccccccc}
\multicolumn{8}{c}{ Volume Percent } \\
$\mathrm{CH}_{4}$ & $\mathrm{CO}$ & $\mathrm{CO}_{2}$ & $\mathrm{H}_{2}$ & $\mathrm{H}_{2} \mathrm{O}$ & $\mathrm{H}_{2} \mathrm{~S}$ & $\mathrm{NH}_{3}$ \\
5 & 18 & 12 & 24 & 39.5 & 0.5 & 1
\end{tabular}

The presence of $\mathrm{H}_{2} \mathrm{~S}$ can lead to $\mathrm{SO}_{2}$ and the $\mathrm{NH}_{3}$ can give $\mathrm{N}_{2}$. However, all four of these will be in relatively low concentration and it was decided to consider the first five species only. If desired, the concentrations of the others can be simply calculated once these five are known, as well as the amount of sulfur and/or nitrogen. 
All gases are assumed to be ideal. Condensed water and carbon are assumed to be pure. For example, the solubility of carbon dioxide in water is ignored. For constant volume problems, the volume of condensed species is ignored in comparison to the gas volumes. That this is generally acceptable is evident from the fact that when $90 \%$ of the original gas has been equilibrated as condensed species, these latter contribute only about $0.5 \%$ to the total volume in the worst case. 


\section{THERMODYNAMIC AND MATHEMATICAL TREATMENT}

Assume a system of $s$ substances, $g$ of which are gases, at pressure $P$, with volume $V$, and thermodynamic temperature $T$. If the system is not at chemical equilibrium, chemical reactions will adjust the number of moles of each substance, $n_{j}$, until equilibrium is attained. At this point the Gibbs energy, G, will have become a minimum if the pressure and temperature are kept constant (ref 1, p 209). If, instead, the volume and temperature are kept constant, the Helmholtz energy, A, will have become a minimum, (ref 1, p 208). The $s-g \geq 0$ substances are condensed phases and are assumed to be pure and immiscible with one another. The gases are assumed to be ideal and insoluble in the condensed phases.

The Gibbs energy may be expressed as the sum of the contributions from each substance.

$$
G=\sum_{1}^{s} n_{i} \mu_{i}
$$

The $\mu_{j}$ are Gibbs energies per mole and are known as the partial molar Gibbs energies or the chemical potentials (ref 1, pp 214,215). For the $g$ gases in an ideal mixture the chemical potentials are a function of the partial pressures, $p_{i}$ (ref 1, p 261).

$$
\mu_{i}=\mu_{i}^{o}+R T \ln p_{i}
$$


The $\mu_{i}^{\circ}$ are constants at fixed temperature and represent the Gibbs energy of one mole of pure ideal gas at 0.101325 megapascals (one atmosphere) pressure. For pure condensed phases the $\mu_{j}$ are merely the $\mu^{\circ}$ for these substances. Consequently, equation (1) can now be rewritten.

$$
G=\sum_{1}^{s} n_{i} \mu_{i}^{0}+R T \sum_{1}^{g} n_{i} \ln p_{i}
$$

Note that the first g subscripts have been assigned to the gases. The partial pressures are equal to the product of the mole fractions, $n_{i} / n_{g}$, and the total pressure.

$$
\begin{gathered}
p_{i}=\left(n_{i} / n_{g}\right) p \\
n_{g}=\sum_{1}^{g} n_{i}
\end{gathered}
$$

Thus, equation (3) may be rewritten.

$$
G=\sum_{T}^{s} n_{i} \mu_{i}^{o}+R T \sum_{T}^{g} n_{i} \ln \left(n_{i} P / n_{g}\right)
$$

The $\mu_{i}$ may be evaluated by considering compounds. For example, the compound $A_{x} B_{y}$ may be made, in principle, from its elements, $A$ and $B$, according to the following chemical reaction.

$$
x A+y B \rightarrow A_{x} B
$$


The Gibbs energy change for the reversible formation of one mole of $A_{x} B_{y}$ is given by $\Delta G_{f}^{\circ}$ with all the substances in the standard states (ref $1, p 283)$.

$$
\Delta G_{f}^{\circ}=\mu_{A B}^{\circ}{ }^{-}-x \mu_{A}^{\circ}-y \mu_{B}^{\circ}
$$

But for an equilibrium among these three substances, the $\Delta G_{f}^{\circ}$ is related to the equilibrium constant (ref 1, p 283).

$$
\Delta G^{\circ}=-R T \ln k_{f}
$$

Here $k_{f}$ is the equilibrium constant for formation of one mole of substance $A_{x} B_{y}$, and $R$ is the molar gas constant. Consequently, one can express the chemical potential of a compound in terms of the absolute chemical potentials of its elements and the equilibrium constant of formation.

$$
\mu_{A_{x} B_{y}}^{\circ}=x \mu_{A}^{\circ}+y \mu_{B}^{\circ}-R T \ln k_{f}
$$

For the general case let $k_{i}$ represent the equilibrium constant of formation for the $i$-th substance.

$$
\mu_{i}=\sum_{j=1}^{e} v_{i j} \mu_{j}^{o}-R T \ln k_{i}
$$

The summation is over all e elements present in the system, with $v_{i j}=0$ for any element, $j$, not present in substance $i$. Furthermore, this expression may be used for substances which are themselves chemical elements by recognizing that for these $\ln k_{j}=0$. Using these ideas, the first term in equation (6) may be rewritten.

$$
\sum_{l}^{s} n_{i} \mu_{i}^{o}=\sum_{i=1}^{s} n_{i}\left\{\sum_{j=1}^{e} v_{i j} \mu_{j}^{o}-R T \ln k_{i}\right\}
$$


It can be shown that the right hand side here can be arranged as follows.

$$
\sum_{1}^{s} n_{i} \mu_{i}^{\circ}=\sum_{j=1}^{e} \mu_{j}^{\circ} \sum_{i=1}^{s} n_{i} v_{i j}-R T \sum_{i=1}^{s} n_{i} \ln k_{i}
$$

Because the elements are neither destroyed nor created by shifts among the $n_{j}, \sum n_{i} v_{i j}=E_{j}$, the number of gram atoms of element $j$ originally introduced into the system. Consequently, the first term on the righthand side of equation ( 8 ) is given by

$$
\sum_{j=1}^{e} \mu_{j}^{0} E_{j}=G^{\circ}
$$

where $G^{\circ}$ is the absolute Gibbs energy due to the elements, a constant. Therefore, the sum of Gibbs energies for all the substances in standard states is given by the following.

$$
\sum_{1}^{5} n_{i} \mu_{i}^{0}=G^{0}-R T \sum_{1}^{s} n_{i} \ln k_{i}
$$

This may be used in (6).

$$
G=G^{0}-R T \sum_{1}^{s} n_{i} 1 n k_{i}+R T \sum_{1}^{g} n_{i} \ln \left(n_{i} P / n_{g}\right)
$$

The right-hand member may be rearranged to give a new function, $\Gamma_{G}$. 


$$
\Gamma_{G}=\frac{G-G^{\circ}}{R T}=\sum_{1}^{g} n_{i} \ln \left(n_{i} P / n_{g}\right)-\sum_{1}^{S} n_{i} \ln k_{i}
$$

Now, because $G^{\circ}, R$, and $T$ are constants, minimizing $\Gamma_{G}$ wi 11 minimize $G$.

Turning at this point to the problem of equilibrium at constant volume and temperature, use is made of the relationship between $G$ and $A$ (ref 1, p 202).

$$
A=G-P V
$$

Use of equation (10) gives an expression which will lead to one that is similar to that in (11).

$$
A=G^{\circ}-R T \sum_{i}^{s} n_{i} l n k_{i}+R T \sum_{i}^{g} n_{i} l n\left(n_{i} P / n_{g}\right)-P V
$$

Assuming that the volume of the condensed phases is negligible compared to that of the gases permits using the (ideal) gas volume for $V$.

$$
P V=n_{g} R T
$$

At the same time it is possible to replace the variable $P$.

$$
A=G^{\circ}-R T \sum_{1}^{s} n_{i} \ln k_{i}+R T \sum_{1}^{g} n_{i} \ln \left(n_{i} R T / V\right)-n_{g} R T
$$

In view of equation (5) the last term may be put inside the gas summation and the expression rearranged to define the function $=\Gamma_{A}$.

$$
\Gamma_{A}=\frac{A-G^{\circ}}{R T}=\sum_{i}^{g} n_{i}\left[\ln \left(n_{i} R T / V\right)-1\right]-\sum_{1}^{S} n_{i} \ln k_{i}
$$


Minimization of $\Gamma_{A}$ also minimizes $A$.

The problem of equilibration has now been shown to require minimization of $\Gamma_{G}$ or $\Gamma_{A}$ respectively for constant pressure or constant volume. However, these minimizations with respect to the $n_{i}$ must be carried out subject to constraints: 1. The chemical elements are conserved as previousiy noted, and, 2 . No $n_{j}$ may be less than zero. The constraints may be expressed as follows.

$$
\begin{array}{rlrl}
L_{j}=\sum_{i}^{s} n_{i} i j-E_{j}=0 & j=1(1) e \\
n_{i} \geq 0 & i=r(1) s
\end{array}
$$

There are e functions, $L_{j}$, each of which expresses the conservation of element $j$ such that the $E_{j}$ equals the number of gram atoms of that element in the system. The $E_{j}$ are determined from the initial composition. As before, $i j$ is the subscript for the element $j$ in substance $i$. Constraint (18) is handled in this development by replacing negative estimates of gaseous constituents by small positive numbers. A negative $n_{i}$ for a condensed phase assumed to be present indicates the absence of that phase and is retained as an indicator of that fact.

The method of minimization adopted here is the classic one using Lagrangian multipliers, $\lambda_{j}$, [6]. To minimize $\Gamma$ form the function $F$ by multipiying each of the $L_{j}$ by $\lambda_{j}$ and adding to $\Gamma$. 


$$
\begin{aligned}
& F_{G}=\sum_{l}^{g} n_{i} \ln \left(n_{i} P / n_{g}\right)-\sum_{l}^{s} n_{i} \ln k_{i}+\sum_{l}^{e} \lambda_{j}\left[\sum_{l}^{S} n_{i} v_{i j}-E_{j}\right] \\
& F_{A}=\sum_{l}^{g} n_{i} \ln \left(n_{i} R T / V\right)-\sum_{l}^{s} n_{i} \ln k_{i}+\sum_{l}^{e} \lambda_{j}\left[\sum_{l}^{S} n_{i} v_{i j}-E_{j}\right]
\end{aligned}
$$

Minimization of $F_{G}$ will be treated first in detail. It will be seen later that a few simple changes in the equations will suffice to minimize $F_{A}$.

Setting the appropriate partial derivatives of $F_{G}$ equal to zero results in three sets of equations, one set for the gases, one for the condensed phases, and one for the elements.

$$
\begin{array}{ll}
f_{i}=\ln n_{i}-\ln n_{g}+\ln \left(P / k_{j}\right)+\sum_{j=1}^{e} \lambda_{j} v_{i j}=0 & i=1(1) g \\
f_{i}=\ln k_{i}+\sum_{j=1}^{e} \lambda_{j} v_{i j}=0 & j=(g+1)(1) s \\
f_{i}=\sum_{i=1}^{s} n_{i} v_{i j}-E_{j} & j=1(1) e
\end{array}
$$

It can be seen that there are $s+$ e equations, sufficient to completely determine the $s n_{i}$ and the e $\lambda_{j}$. The variable $n_{g}$ is a defined function which is calculated when the $n_{i}$ have been estimated.

Equations (21) are nonlinear and an iterative procedure, NewtonRaphson [7], is used. In summary, this method iterates from initial estimates of the $n_{i}$ and the $\lambda_{j}$ to a final set which satisfies some stopping criterion. The iterations may be expressed by use of a matrix equation [13]. 


$$
x_{t+1}=x_{t}-j_{t}^{-1} f_{t}
$$

Here $x$ and $f$ are column matrices (vectors) representing the unknowns and the functions (21) through (23). Subscript $t$ indicates that the values used are from the t-th trial. J is the Jacobian of the f's, a square matrix with elements equal to the partial derivatives of the functions, $f$, with respect to the $n_{j}$ and the $\lambda_{j}$.

There are a variety of types of elements in the Jacobian. Equations (21) yield the following entries.

$$
\begin{array}{ll}
\frac{\partial f_{i}}{\partial n_{i}}=\frac{1}{n_{i}}-\frac{1}{n_{g}} & \{=1(1) g \\
\frac{\partial f_{i}}{\partial n_{k}}=-1 / n_{g} & \left\{\begin{array}{l}
i=1(1) g \\
k=1(1) s \\
k \neq i
\end{array}\right. \\
\frac{\partial f_{i}}{\partial \lambda_{j}}=\nu_{i j} & \left\{\begin{array}{l}
i=1(1) g \\
j=1(1) e
\end{array}\right.
\end{array}
$$

Equations (22) yield the following.

$$
\begin{array}{ll}
\frac{\partial f_{i}}{\partial n_{k}}=0 & \left\{\begin{array}{l}
j=g+1(1) s \\
k=1(1) s
\end{array}\right. \\
\frac{\partial f_{i}}{\partial \lambda_{j}}=v_{i j} & \left\{\begin{array}{l}
i=g+1(1) s \\
j=1(1) e
\end{array}\right.
\end{array}
$$

Equations (23) yield the following. 


$$
\begin{aligned}
& \frac{\partial f_{j}}{\partial n_{i}}=v_{i j} \quad\left\{\begin{array}{l}
j=1(1) e \\
i=1(1) s
\end{array}\right. \\
& \frac{\partial f_{j}}{\partial \lambda_{k}}=0 \quad\left\{\begin{array}{l}
j=1(1) e \\
k=1(1) e
\end{array}\right.
\end{aligned}
$$

Expression (25) gives nonzero values to the first g Jacobian elements along the diagonal. Expressions (27) and (29) may be combined.

$$
\frac{\partial f_{i}}{\partial \lambda_{j}}=v_{i j} \quad\left\{\begin{array}{l}
i=1(1) s \\
j=1(1) e
\end{array}\right.
$$

Expressions (26), (30), and (32) show that these elements are symmetrically disposed with respect to the diagonal. Since all other elements are zero, $J$ is symmetric. This is an advantage for some methods of calculating the inverse.

These results are easily modified for equilibria at constant volume. The functions (21) are replaced by (33), but (22) and (23) are retained.

$$
f_{i}=\ln n_{i}+\ln \left(\frac{R T}{v}\right)-\ln k_{i}+\sum_{j=1}^{e} \lambda_{j} v_{i j} i=1(1) g
$$

Of the Jacobian elements, those in (25) and (26) are changed, replaced by (34) and (35). 


$$
\begin{array}{ll}
\frac{\partial f_{i}}{\partial n_{i}}=1 / n_{i} & i=1(1) g \\
\frac{\partial f_{i}}{\partial n_{k}}=0 & \left\{\begin{array}{l}
i=1(1) g \\
k=1(1) s \\
k \neq i
\end{array}\right.
\end{array}
$$




\section{GENERAL STATEMENT OF THE ALGORITHM}

In principle there is no difficulty obtaining equilibrium compositions from the development of the previous section. A problem is defined by giving values for the constant temperature and the constant pressure (or volume) and for the composition of the test gas in moles of each substance. * From the latter the number of gram atoms, $E_{j}$, of each chemical element may be calculated. From the formulae of the substances the $v_{i j}$ are also determined. The equilibrium constants of formation may be obtained from the literature. One needs only initial estimates of the $n_{i}$ and the $\lambda_{j}$ in order to proceed.

1. Choose initial estimates.

2. Evaluate the functions, equations (21) to (23), using the initial estimates.

3. Calculate the elements of the Jacobian, equations (25) to (32).

4. Invert the Jacobian.

5. Calculate the new estimates from equation (24).

6. Check the estimates against the stopping criterion.

7. Depending upon the result of step 6 , either stop or repeat steps 2 through 6 using the new estimates for evaluation purposes.

$*$

In the later section about using the program the instructions ask for mole fractions or percentages although these data are treated as moles. Experience with COLGAS has shown that when $n_{g}$ is much less or much greater than one, difficulty with over- or underflow may occur. 
As straightforward as this procedure is, there are a number of practical points associated with these steps which are worth commenting on. However, the handling of the practical problems depends upon the general aims of the program. Therefore, although some general remarks will be made, it must be understood that the particular procedure adopted in this report is based upon the restricted nature of the problems being solved.

Choosing the Estimates. The program to be developed was to give a "one shot" solution. That is, a single run would produce only a single answer. A different temperature and/or a different pressure (or volume) or test gas composition will require a new run. Consequently, the program has no prior experience to build upon as is used in some programs $[8,14]$. It was decided to use the test gas composition as the initial estimates for the substances, and this has turned out to be satisfactory. For each $\lambda_{j}$ zero has been a satisfactory initial estimate.

There are two versions of the program in the same listing. The commonly used version has a short printout. Either the short or the long printout is obtained by an appropriate response to the initial query at the terminal. The long version permits the operator to suggest which of the four combinations of condensed species situations is believed to be correct. It then allows input of a set of initial estimates different from that used automatically by the program. These alternatives have been provided so that on occasions of non-convergence an operator may try to redo the iterations with a better starting situation. 
Evaluating the Functions. Equations (21) to (23) present no problems beyond obtaining values for the equilibrium constants of formation for compounds in the system. (The total number of moles of gases, $\mathrm{n}_{\mathrm{g}}$, is evaluated anew at each iteration using equation (5)). The equilibrium constants used in the program, except for liquid water, come from the JANAF Tables [15] and are discussed in a separate section.

Calculating the Elements of the Jacobian. Examination of equations (25) to (32) shows that the only elements varying in value from iteration to iteration are the elements of the upper left $5 \times 5$ submatrix. These will require recalculation during the iteration. All other elements are constant integers and need not be re-evaluated. However, if the presence or absence of a condensed phase turns out to be different than assumed, the presence or absence of the appropriate constant elements must be adjusted.

Inverting the Jacobian. There is an extensive literature on the inversion of matrices, particularly symmetric ones [16]. It is tempting to seek a direct analytical solution with perhaps the possibility of avoiding some round-off error in the computer. In fact, at constant volume and for the case where solid carbon is present, but liquid water is not, it is relatively simple to do this using either an LP or an LDR decomposition of the Jacobian [17]. There is a minor advantage to this beyond the possibility of reducing the round-off error. Some of the expressions for the $n_{i}$ contain functions of them which may be replaced by the $E_{j}$ constants for hydrogen and oxygen. This should improve the accuracy of 
the estimates and perhaps reduce the number of required iterations. However, when the condensed phase situation is reversed, some of the expressions for the estimates become quite complicated and hardly worth evaluating directly. Although not essential, it is desirable to handle all varieties of condensed phase situations in the same way for simplicity of programming. This is particularly true when using the BASIC programming language because of the one-statement matrix inversion procedure provided. A direct analytical solution was, therefore, not used.

Calculating the New Estimates. As is well known, the Newton-Raphson procedure often overcorrects in the early stages, particularly if the initial estimates are somewhat far from the mark. This results in divergence. To avoid this a common procedure is to modify the correction term in the estimating equation, (24), by a weighting factor, $k$, less than unity.

$$
x_{t+1}=x_{t}-k_{t} J_{t}^{-1} f_{t}
$$

In many nonlinear equation problems it is adequate to use $k=0.5$ in the early stages and to change it to unity later on. In running this program it was found that this was not always sufficient. This difficulty was overcome by making $k$ a variable function of $t$, the number of the irial. A sinusoidal function of $t$ sets $k$ equal to about 0.01 for $t$ $=1$, to 0.5 for $t=8$, and to 1.0 for $t=16$. The value of $k$ remains at unity for any further iterations. This is done only for the gaseous 
constituents. Experience with the algorithm has shown that the estimates of the Langrangian multipliers converge easily with $k=1.0$ at all stages.

Sometimes new estimates of the gaseous moles become negative. This not only violates the constraint, equation (18), but it cannot be tolerated when evaluating the functions, $f_{i}$, which contain $/ n n_{j}$. Transformations may avoid this problem, $y=n^{2}$ [4] or $y=\ln n$ [5], but introduce numerous back and forth transformation steps in the algorithm which were thought to be undesirable. The algorithm reported here replaces such numbers with a very small number, originally $1 \times 10^{-7}$. It was found that this occasionally led to difficulty when the size of the correction was larger than this figure. A loop of repeated values could result with continually negative estimates for the same $n_{j}$ leading to a lack of convergence. This difficulty was partially overcome by replacing the 7 in the exponent by a random number distributed uniformly between 7 and 10 inclusive. This choice occasionally leads to a new difficulty with some processors. During the matrix inversion step, usually a Gauss-Jordan routine, the product of the five $\left(1 / n_{i}-1 / n_{g}\right)$ is evaluated. If for a given iteration a number of $n_{i}$ estimates become negative the $n_{i}$ product may cause an overflow. This has happened with a compiler for which the exponent of numerical constants is restrained to be within \pm 38 . For a processor with a larger range, say greater than \pm 55 , this difficulty may not arise. 
Checking the Estimates for Stopping. The criterion used here for stopping depends upon the magnitude of the unweighted correction to the $n_{i}$ and the $\lambda_{j}$. The vector $c_{t}$ is the correction and it comes from (24).

$$
c_{t}=J_{t}^{-1} f_{t}
$$

The iterations are considered complete when

$$
\frac{c_{t}}{n_{t}}<5 \times 10^{-5}
$$

for all $n_{i}$ and $\lambda_{j}$. This particular stopping criterion has been criticized, (ref 18, p 520) as not leading necessarily to the same solution as a criterion based upon the derivatives: $f_{i}$ being sufficiently close to zero. However, because the interest here is in the gas composition the criterion given above is preferable. To assure adequate minimization, the pertinent independent chemical equilibria constants are checked for agreement when calculated from Gibbs energies of formation and from the calculated mole fractions. According to Brinkley [23] there are at most $R=N-C$ reactions for $N$ chemical species and $C$ components. In this discussion $C=3$ and $N$ equals 5,6 , or 7 depending upon the case. For case IV, all gas, (see below), $N=5$ and $R=2$. The reactions chosen were the following.

$$
\begin{array}{ll}
\text { A: } & \mathrm{CO}_{2}+\mathrm{H}_{2}=\mathrm{CO}+\mathrm{H}_{2} \mathrm{O} \\
\text { B: } & \mathrm{CO}+3 \mathrm{H}_{2}=\mathrm{CH}_{4}+\mathrm{H}_{2} \mathrm{O}
\end{array}
$$

When $C(s)$ is present, reaction $C$ is included, and for liquid water reaction $D$. 


$$
\begin{array}{ll}
\text { C: } & \mathrm{CO}_{2}+\mathrm{C}(\mathrm{s})=2 \mathrm{CO} \\
\text { D: } & \mathrm{H}_{2} \mathrm{O}(\mathrm{l})=\mathrm{H}_{2} \mathrm{O}(\mathrm{g})
\end{array}
$$

Terminating the Iterations. When the stopping criterion, equation (38) has been satisfied for all $n_{j}$ and $\lambda_{j}$ one set of iterations is complete. The problem may not be solved, however. In order to perform the calculations a choice had to be made among the possible combinations of condensed species situations as shown in Table 2.

Table 2. Condensed Phase Cases

$$
\begin{aligned}
& \mathrm{H}_{2} \mathrm{O}(1) \\
& \text { YES NO } \\
& \begin{array}{lll}
\text { YES I - } 8 & \text { II - 7 }
\end{array} \\
& C(s) \\
& \text { NO } \quad \text { III - } 9 \text { IV - } 8
\end{aligned}
$$

Here the yes-no tabulations refer to the presence or absence of the phase at the top or at the left. The Roman numerals are used to identify the cases, and the Arabic numerals show the number of functions, $f_{i}$, and correspond to the order of the relevant Jacobian.

Solving the seven-equation system corresponding to case II, say, has assumed the presence of solid carbon and the absence of liquid water. However, this assumption may not be correct. Therefore, after going through steps 1 to 7 and deciding to stop, it is necessary to check the assumption of case II. If liquid water is really present 
and/or solid carbon is really absent as suggested by the final $n_{j}$, then the appropriate case must be chosen and the iterations redone. There are, therefore, two hierarchies of iterations, one on the $n_{j}$ and one on the cases. When the final $n_{i}$ are found to be consistent with the case assumed, the calculation is finally finished. Details of checking case consistency are covered in the section on DETAILS OF THE ALGORITHM. 
APPLICATION TO A SIMPLIFIED COAL GASIFICATION SYSTEM

The work shown in this report was undertaken to provide results with atmospheres used for testing materials to be used in coal gasification plants. For simplicity the problem was limited to one in which an initial gas mixture was made from two or more of the following: $\mathrm{CH}_{4}, \mathrm{CO}$, $\mathrm{CO}_{2}, \mathrm{H}_{2}$, and $\mathrm{H}_{2} \mathrm{O}$ at some temperature, $\mathrm{T}$. The test may be carried out dynamically in which case constant pressure is assumed. A static test implies constant volume. Constant pressure will be assumed here. From what has gone before, extension to constant volume will be obvious.

The first step is to set down the pertinent functions, according to equations (21) through (23) of the second section, but it is necessary to decide upon allowable condensed states. Because conditions of test will not permit the existence of ice, only liquid water need be considered. The conditions will be above the critical temperatures of the other four substances so no other solid or liquid phase for these need be considered. However, decomposition of $\mathrm{CH}_{4}$ and disproportionation of $\mathrm{CO}$ can produce solid carbon. Consequently, there are two condensed phases to consider, liquid water and solid carbon. Examination of the simultaneous equations in the light of this shows that $n_{C}$, the number of moles of solid carbon, appears only once, and that in the equations (23) corresponding to that element. Allowing indices one through five to refer to the gases in the order mentioned above

$$
n_{1}+n_{2}+n_{3}+n_{c}-c=0
$$


Here $C$ is the $E_{j}$ for the element carbon. It is unnecessary, therefore, to solve for $n_{c}$ iteratively. Instead the equation for the constraint due to the element carbon will be deleted. When the other $n_{j}$ have alt been determined, $n_{c}$ may be calculated from (39). For case II (solid carbon only) the functions to be used are the following.

$$
\begin{aligned}
& f_{1}=\ln n_{7}-\ln n_{g}-1 n k_{1}+4 \lambda_{h} \\
& f_{2}=\ln n_{2}-i n n_{g}-\ln k_{2}+\lambda_{0} \\
& f_{3}=\ln n_{3}-\ln n_{g}-\ln k_{3}+2 \lambda_{0} \\
& f_{4}=\ln n_{4}-\ln n_{g}-\ln k_{4}+2 \lambda_{h} \\
& f_{5}=\ln n_{5}-\ln n_{g}-\ln k_{5}+2 \lambda_{h}+\lambda_{0} \\
& f_{6}=4 n_{7}+2 n_{4}+2 n_{5}-n \\
& f_{7}=n_{2}+2 n_{3}+n_{5}-0
\end{aligned}
$$

Here $h$ and $o$ are the $E_{j}$ for hydrogen and oxygen.

Equations (25) to (31) of the second section read simply to the Jacobian. 


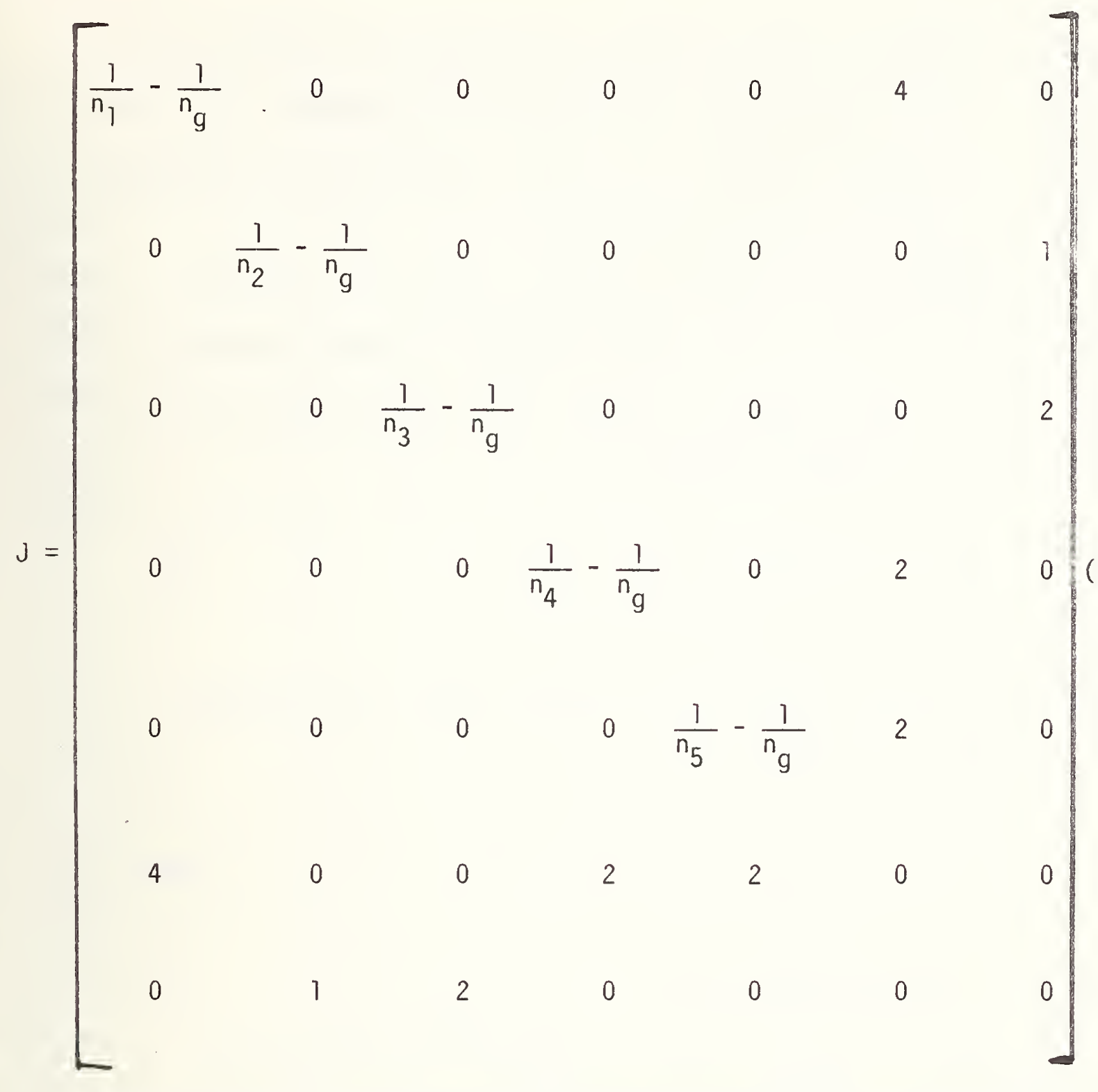

The functions of equation (40) and the inverse of the Jacobian (41) are the needed entries for the right hand side of equation (24) of the second section. 
The development of case II gives the smallest set of equations to be solved by iteration and give rise to the "basic" Jacobian. This is a $7 \times 7$ upper left submatrix common to the cases. Consequently, the elements in it may be defined without regard to case.

The development here was for a particular case. The one with condensation, Case I, with both condensed phases present, follows by adding terms for liquid water to $f_{6}$ and $f_{7}: 2 n_{7}$ and $n_{7}$ respectively. A function for liquid water is needed.

$$
f_{8}=2 \lambda_{h}+\lambda_{0}=\ln k_{\ell}
$$

The pertinent Jacobian is equation (41) with another row and column added. The row is given by $j_{8}$.

$$
j_{8}=\{0,0,0,0,0,2,1,0\}
$$

The column is the transpose of this.

Case III, with liquid water but no solid carbon, requires $\mathrm{f}_{8}$ and $n_{w}$ but has no $n_{c}$. Because there is no $n_{c}$ equation (39) becomes

$$
f_{9}=n_{1}+n_{2}+n_{3}-c
$$

This function must be included as well as a $\lambda_{C}$. $A$ new row and column are added to the Jacobian consisting of ones in the first three elements and zeros elsewhere. This is the largest matrix and has nine rows and columns. 
Case IV, with neither liquid water nor solid carbon, is derivable from Case III by elimination of the eighth row and column. These correspond to liquid water and $\lambda_{\ell}$. Also the function, $f_{8}$, is deleted. The problem of determining equilibrium compositions in the system is then resolved to choosing the appropriate form of the Jacobian, (41), depending upon the case. Deciding the appropriate case for any given problem without any prior knowledge is difficult. As was seen in the previous section, the algorithm given here assumes a starting case and checks the results for consistency with this assumption. 
THERMODYNAMIC DATA

For the five gases, $\mathrm{CH}_{4}, \mathrm{CO}, \mathrm{CO}_{2}, \mathrm{H}_{2}, \mathrm{H}_{2} \mathrm{O}$, the tabular data of the JANAF Tables [15] between 300 and $1400 \mathrm{~K}$ were fitted by least squares to equations of the form

$$
\ln k_{i}=a_{1}+a_{2} \ln T+\sum_{1}^{m} a_{i+2} T^{i}
$$

Here, as stated earlier, $k_{j}$ is the equilibrium constant of formation of the $i$-th compound in its standard state and from its elements in their standard states. The constant for hydrogen is, of course, unity so that the corresponding $\ln k_{j}$ equals zero. The value of $m$ was determined by trials with $m=2(1) 5$. The smallest $m \geq 2$ so that the standard error of the residuals $\leq .001$ was chosen. The form of this equation is similar to that of Barron, Porter, and Hammond [19] but the latter authors used a fixed highest power equal to five. The least squares coefficients were determined with the computer language OMNITAB [20] which has an accurate least squares routine [21].

Liquid water is not included in the JANAF Tables, so resort was had to combining the JANAF data for gaseous $\mathrm{H}_{2} \mathrm{O}, \mathrm{k}_{5}$, with the vapor pressure, $p_{s}$.

$$
\ln k_{\ell}=\ln k_{5}-\ln p_{s}
$$

For the vapor pressure data, Schmidt's tabular values [24] were used and fitted by least squares to an equation of the following form. 


$$
\ln p_{s}=b_{1}+b_{2} / T+\sum_{i=1}^{m} b_{i+2} T^{i}
$$

In this case the data were sufficiently detailed that a tighter criterion could be used for $m$. The smallest $m$ was chosen for which the maximum residual $\leq 0.0005$. The results, $\ln k_{j}$ for the gases and $\ln p_{5}$ for $\mathrm{H}_{2} \mathrm{O}(\ell)$ are shown in the table.

Table 3. Empirical Coefficients for the $\ln k_{i}$ and $\operatorname{Ln} p_{5}$

\begin{tabular}{|c|c|c|c|c|c|}
\hline$a_{1}$ & $a_{2}$ & $a_{3} \times 10^{3}$ & $a_{4} \times 10^{6}$ & $a_{5} \times 10^{9}$ & $a_{6} \times 10^{13}$ \\
\hline 8212.35 & -0.816063 & -10.0801 & 7.73804 & -3.06981 & 5.08552 \\
\hline 13632.3 & 1.8055 & -2.3936 & 0.372836 & -- & --- \\
\hline 47326.7 & 0.0777872 & -0.280706 & 0.0348747 & -- & -- \\
\hline 28786.6 & -0.697311 & -1.45957 & 0.83769 & -0.180286 & --- \\
\hline$b_{1}$ & $b_{2}$ & $b_{3}$ & $b_{4} \times 10^{4}$ & $b_{5} \times 10^{7}$ & $b_{6} \times 10^{10}$ \\
\hline 55.5049 & -9430.74 & -0.159684 & 3.07499 & -3.0549 & 1.24325 \\
\hline
\end{tabular}

The maximum residual for any of the nonzero $\ln k_{i}$ to be used is 0.00186 for $\ln p_{5}$. Program trials with $1 n k$ differing by 0.01 showed absolute values of changes in the computed $n_{1} \leq 0.0001$. The accuracy of the coefficients in the table is quite adequate for the purpose. 


\section{DETAILED ALGORITHM}

Master Flowchart. The details of the algorithm will be described in terms of flowcharts for some sections and with an overall chart showing the relationship of the pieces. It will be noticed that although some sections of the program could be subroutines, they are not. There are no "gosub" and "return" statements. There is no advantage to having formal subroutines here. Replacement of a section is no more difficult than replacing a subroutine because BASIC statements must all have line numbers which must be adjusted in either case. Furthermore, because one cannot fruitfully use dummy variables, one of the advantages of a FORTRAN type subroutine is lost.

The master flowchart is shown as Figure 1. Most of the items are self-explanatory, however, some remarks about others will be useful.

The first major branch point reflects the impossibility of $\mathrm{H}_{2} \mathrm{O}(1)$ existing above its critical temperature, $647.3 \mathrm{~K}$, and below that at total pressures less than its vapor pressure. This is a useful distinction because it rules out two of the four cases, I and III. The choice of II and IV as starting cases for the respective branches resulted from the experience that these led more often to convergence of the first set of iterations. A longer experience may suggest alternate choices. Note that the variable $c_{1}$ is assigned the value of the case number assumed at the start of a set of iterations. This is required for the case-consistency checking section.

The Newton-Raphson iterations follow in either case. These will be treated later by a separate flowchart. Upon successful convergence of 


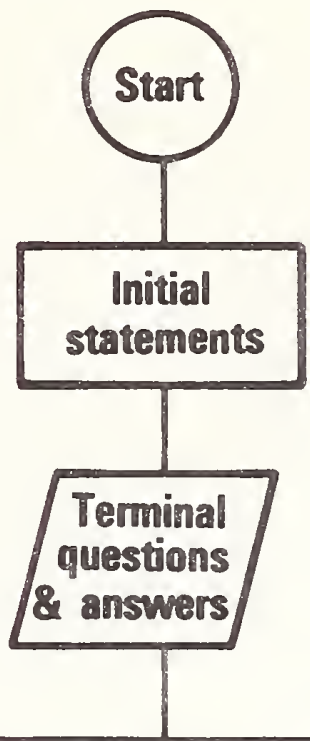

\section{Calculate $\log \mathbf{k}_{\mathrm{p}}$.}

$k_{\text {reaction }}$ for checking.

\& volume or pressure

yes
Assign max size
and constant elements
of basic Jacobian

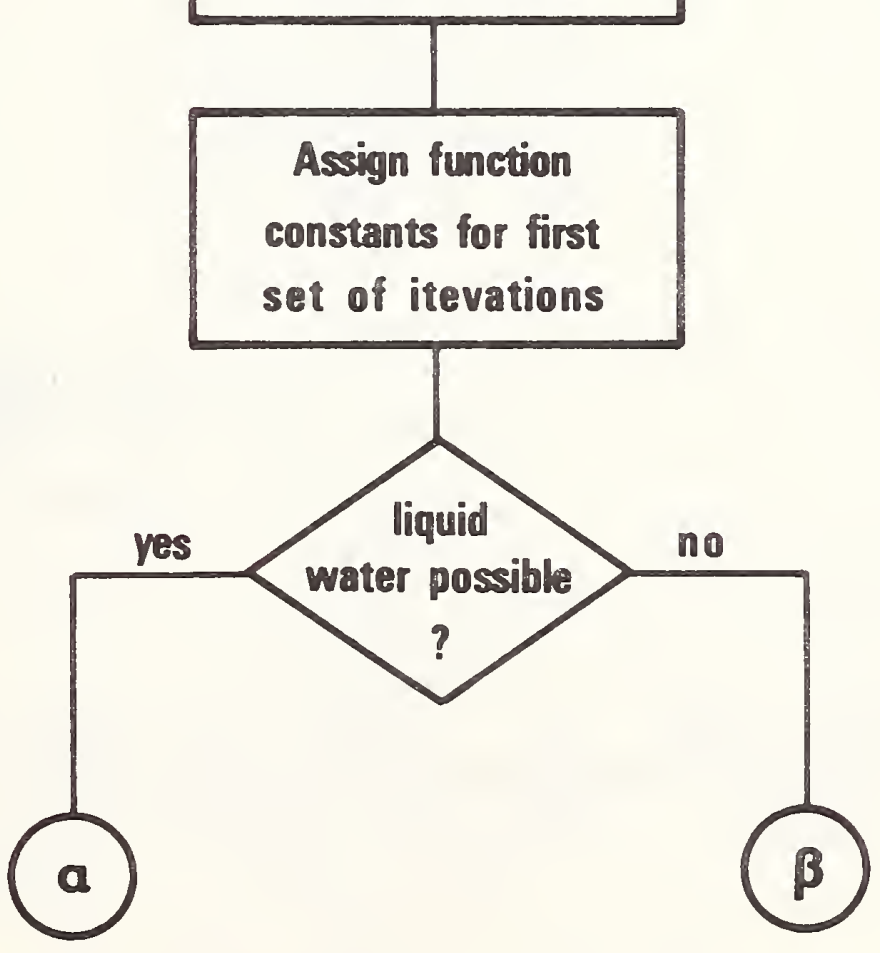

Figure la 


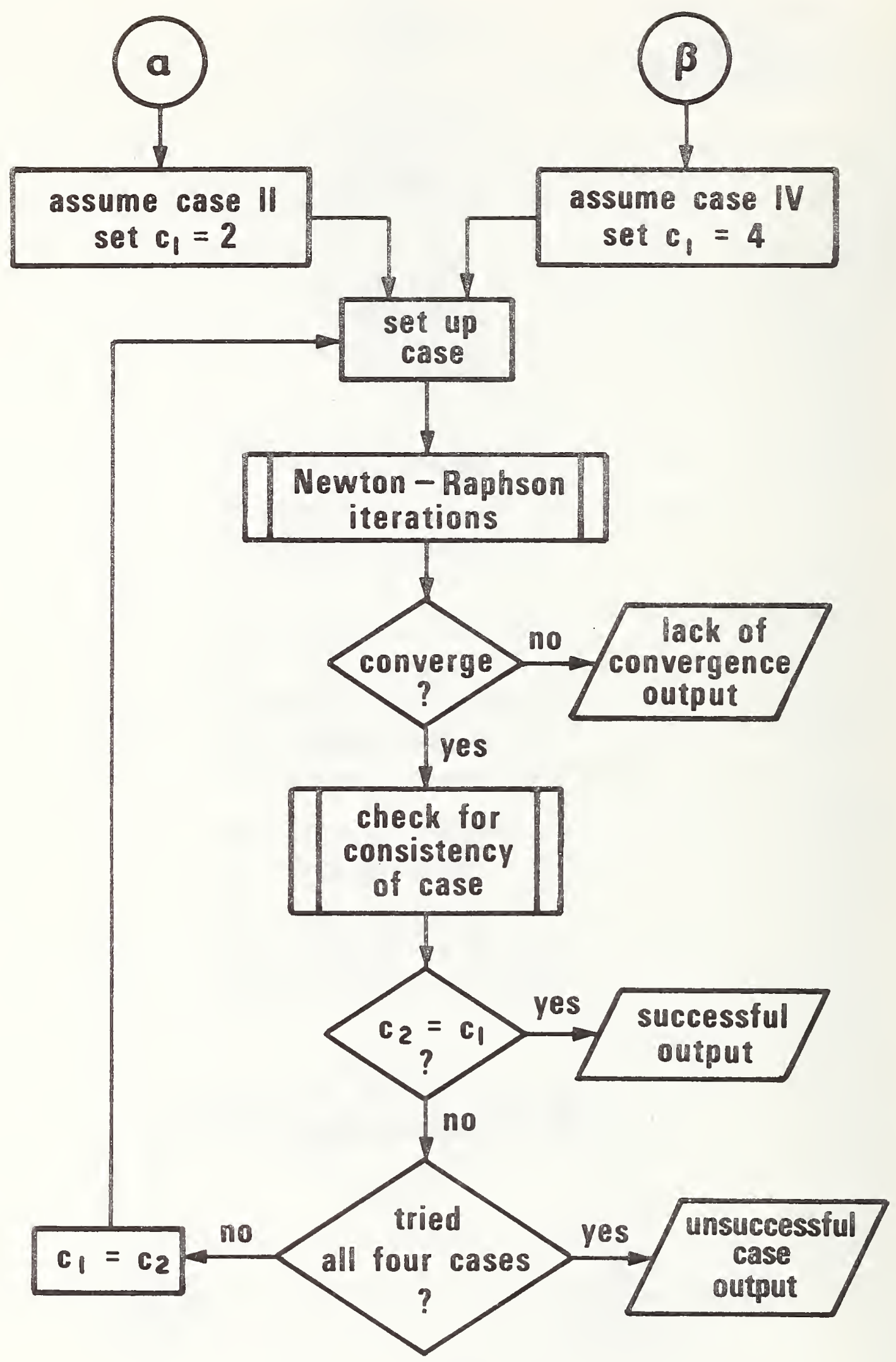

Figure $1 b$ 
the iterations, the next step is to check the case suggested by the results. Upon unsuccessful convergence, the "1ack-of-convergence output" results. The latter not only states lack of convergence but also gives the case number that had been assumed and the last set of iterated results. These outputs are useful if it is desired to try again with a different set of initial estimates.

The case-checking section will be presented in a detailed flowchart. Essentially it computes the case number, $c_{2}$, suggested by the successfully converged results and compares this with $c_{7}$. If they are equal then a "successful output" results which gives the equilibrium gas composition, quantities of liquid water and/or solid carbon if either or both are present, and the changed volume (or pressure). If $c_{2}$ does not equal $c$, then a counter is compared with the number four. If four cases have been tried then an "unsuccessful output" is produced stating this fact. This kind of result has not yet appeared in practice (Apri1 11 , 1978), however, the possibility has been allowed for. If four cases have not yet been tried $c_{1}$ is set equal to $c_{2}$ and the program returns to that case for another set of iterations.

Newton-Raphson Iterations. The flowchart for this section appears in Figure 2. The iteration counter, $t_{7}$, allows up to 30 trials. It has been the usual experience with this program that if convergence has not been reached in 30 iterations, it will not be reached by going beyond this point. Commonly, convergence is attained with between 10 and 20 trials. It would take less, but, for the cautiously slow start enforced by the weighting factor, $k$. 


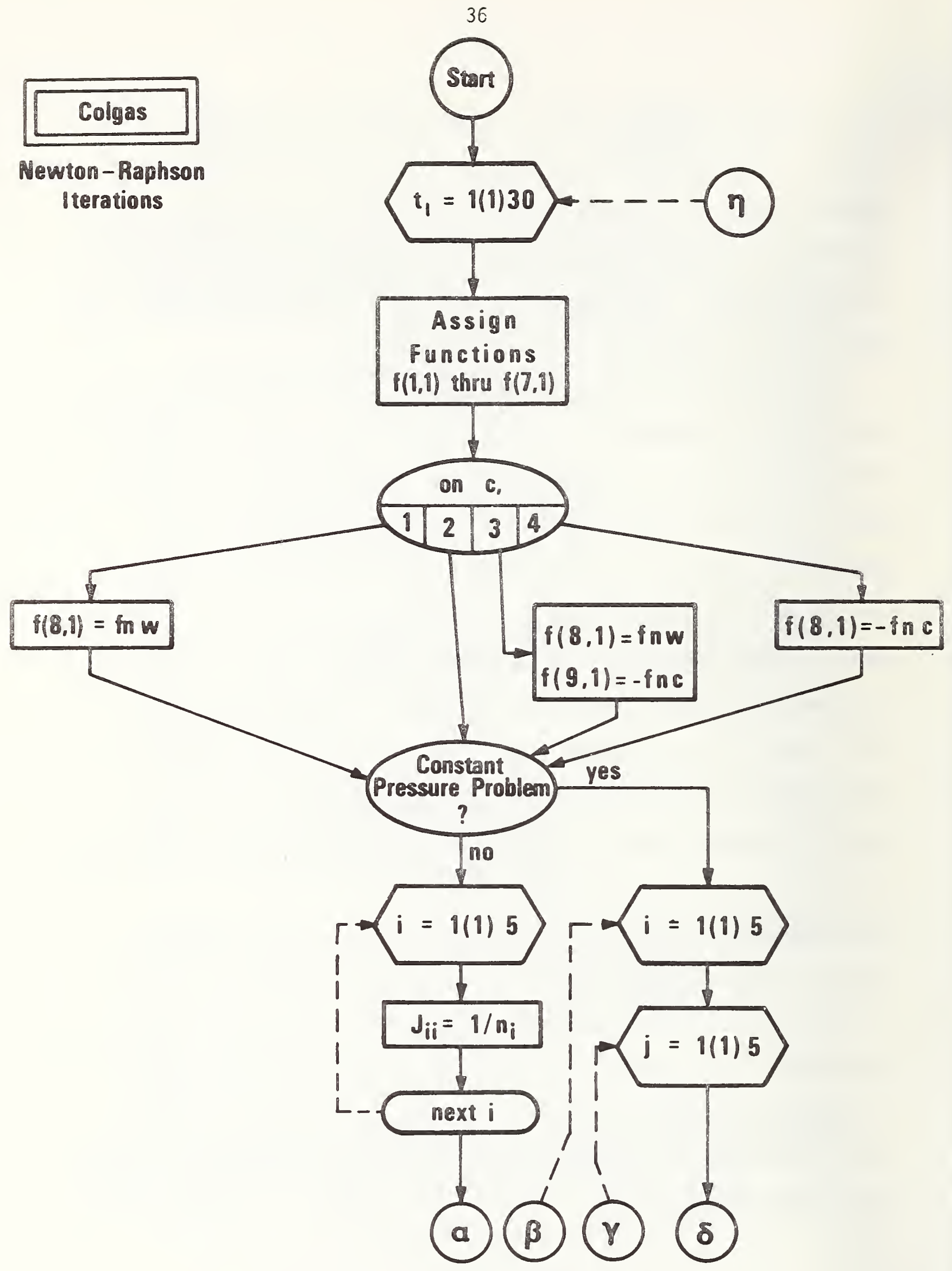

Figure 2a 


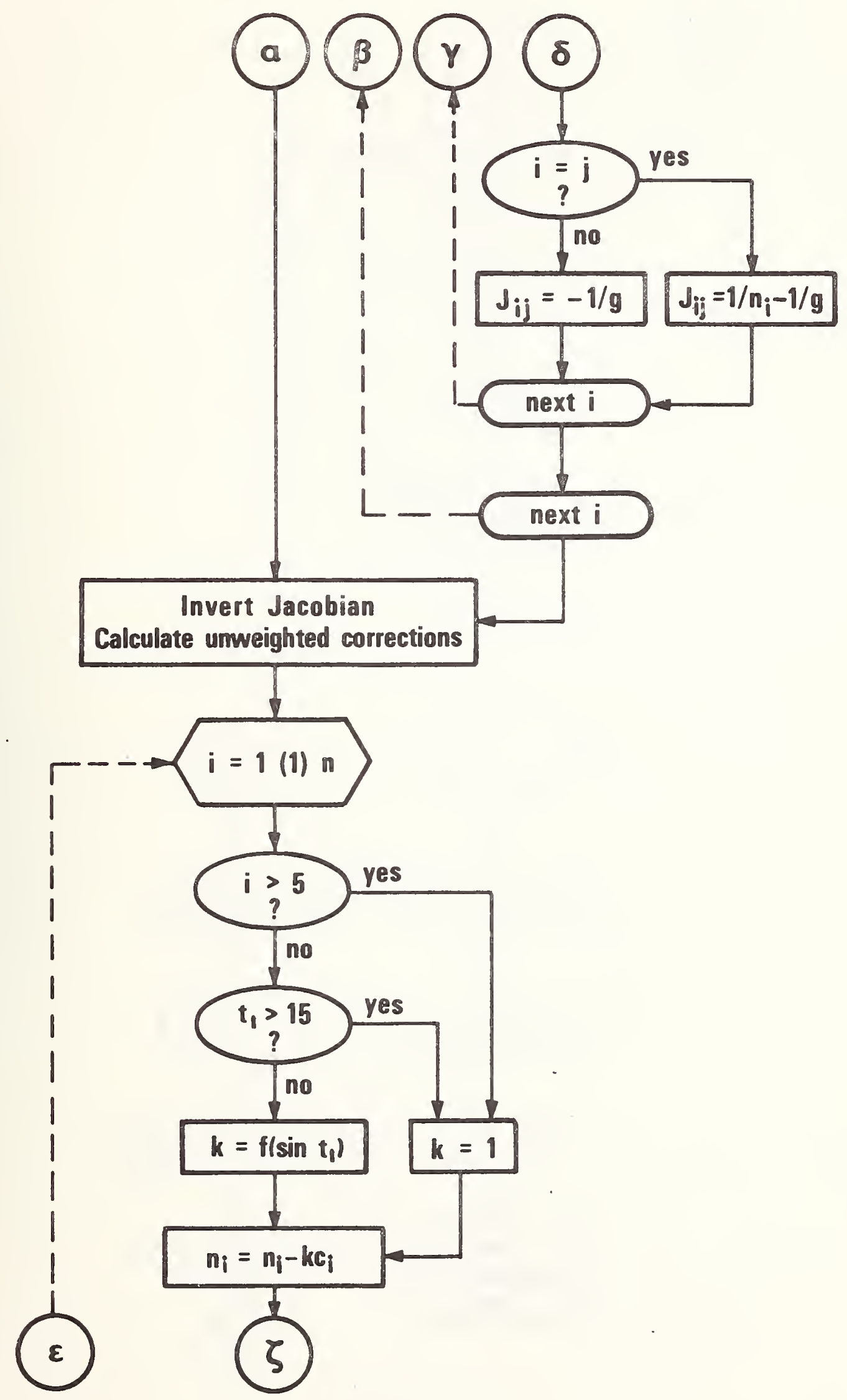

Figure 2b 


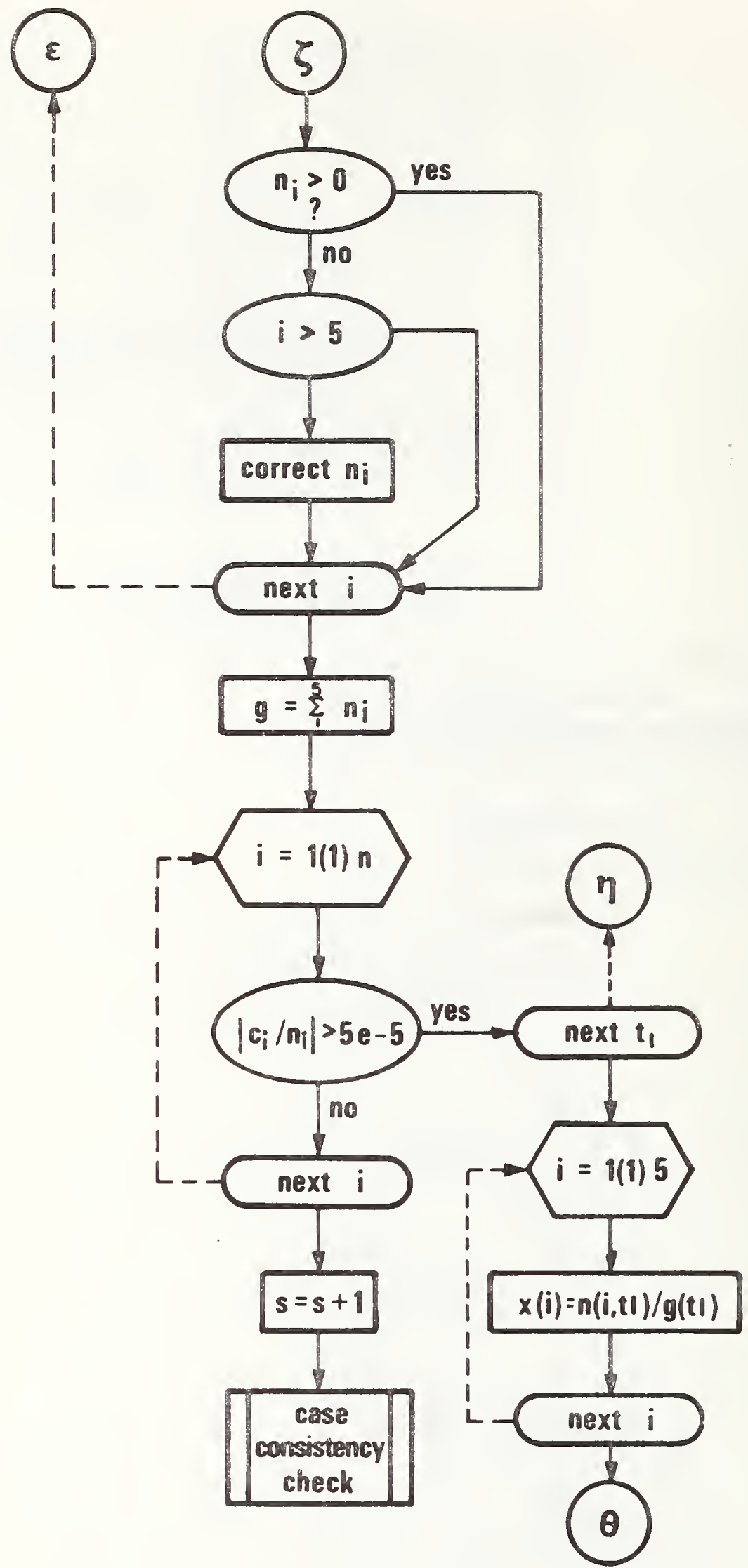

Fiqure 2c 


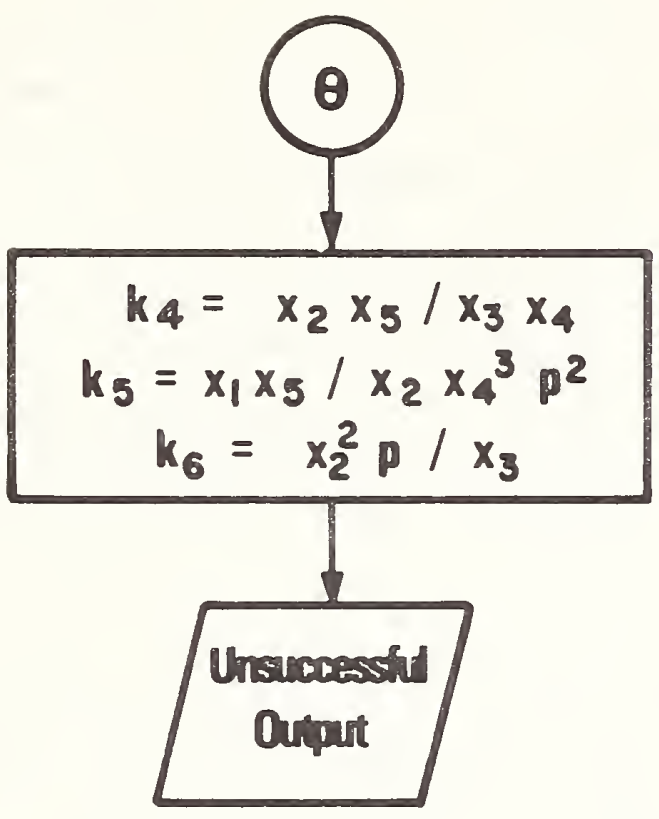

Figure 2d 
Initially, the seven functions which, with slight variations, are common to ali four cases, are evaluated using the previously determined $n_{i}$. The variations required for the different cases are achieved by using two constant muttipliers $b$ and $d$, which are set independently equal to zero or unity depending upon the case. A third constant, e, is the subscript for $\lambda_{C}$, the Lagrangian multiplier for the element carbon in cases III and IV when solid carbon is not present. Since $\lambda_{C}$ is always last in these cases, e is set equal to $n$, the size of the appropriate Jacobian. Next, via an "on $\mathrm{c}_{1}$ " statement, the appropriate remaining functions for cases I, III, and IV are assigned. This is accomplished with the user-defined BASIC functions fnw and fnc.

Following the assignment of the functions, the elements of the upper left $5 \times 5$ submatrix of the Jacobian are evaluated. As stated earlier, these depend upon whether the problem is for constant pressure or constant volume.

Once evaluated, the Jacobian is inverted and unweighted corrections calculated. The next part of the diagram introduces the weight factor, $k$, which is applied only to the five gases and then up to only trial 15. Following the correction of all $n_{j}$, the number of moles of gas is caiculated.

The next operation is a loop testing all $\mathrm{n}_{j}$ against the stopping criterion. If successful for all, s, the counter of iteration sets is incremented by one and the calculation proceeds to testing the condensed phase case found against the one assumed. 
Case-Consistency Check. In Figure 3, this section begins by calculating mole fractions for the five gases. These are used to calculate equilibrium constants for the three independent reactions and the partial pressure of water. As stated earlier these are used to check the final solution found by minimization of the reduced relative Planck function. (See the subsection on Checking the Estimates for Stopping.) Although only $k_{6}$, for the disproportionation reaction, is used in this section they are all calculated together.

The determination of the case found by the converged iterations depends upon the case that was assumed. If that was case III or IV then the conservation of the element carbon was enforced. In these circumstances, by comparing the equilibrium constant for disproportionation (chemical equation C) calculated with the mole fractions with that calculated from the Gibbs energies of formation the need for solid carbon can be determined. On the other hand, if carbon is assumed present then the defined function fnc indicates whether its presence has been verified.

For liquid water cases I and III go together by assuming its presence. For those cases the sign of $\mathrm{n}_{1}$ is the indicator. For cases II and IV, $\mathrm{n}_{1}$ is not calculated, therefore, the partial pressure of water is checked against the vapor pressure.

The value of $c_{2}$ is built up by an initial assignment and addition as the program works its way through this section. Upon reaching its final value, $c_{2}$ is compared with $c_{1}$ as stated earlier. Before returning to the appropriate case, if that is necessary, $c_{1}$ is set equal to $c_{2}$. 

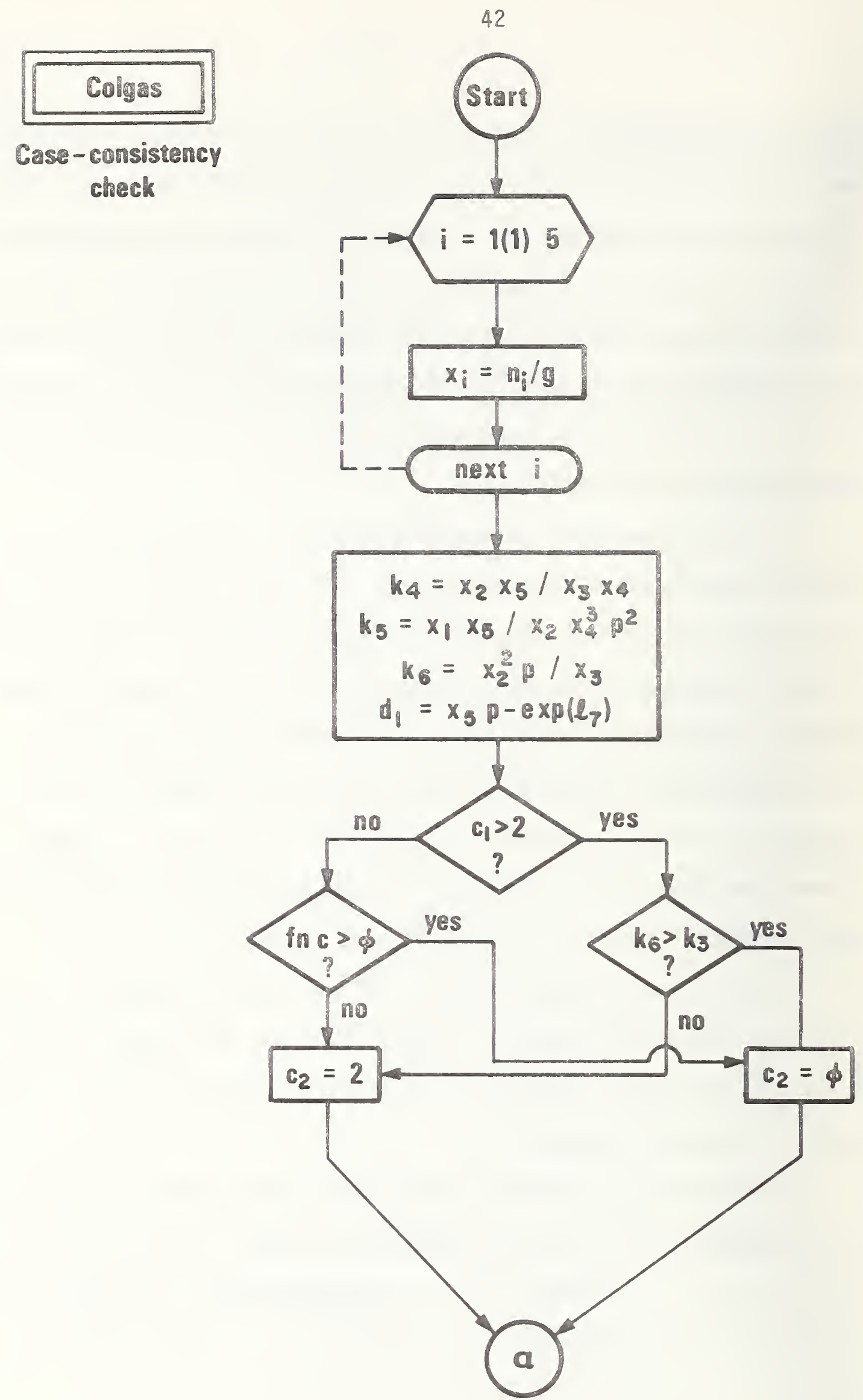

Figure $3 a$ 


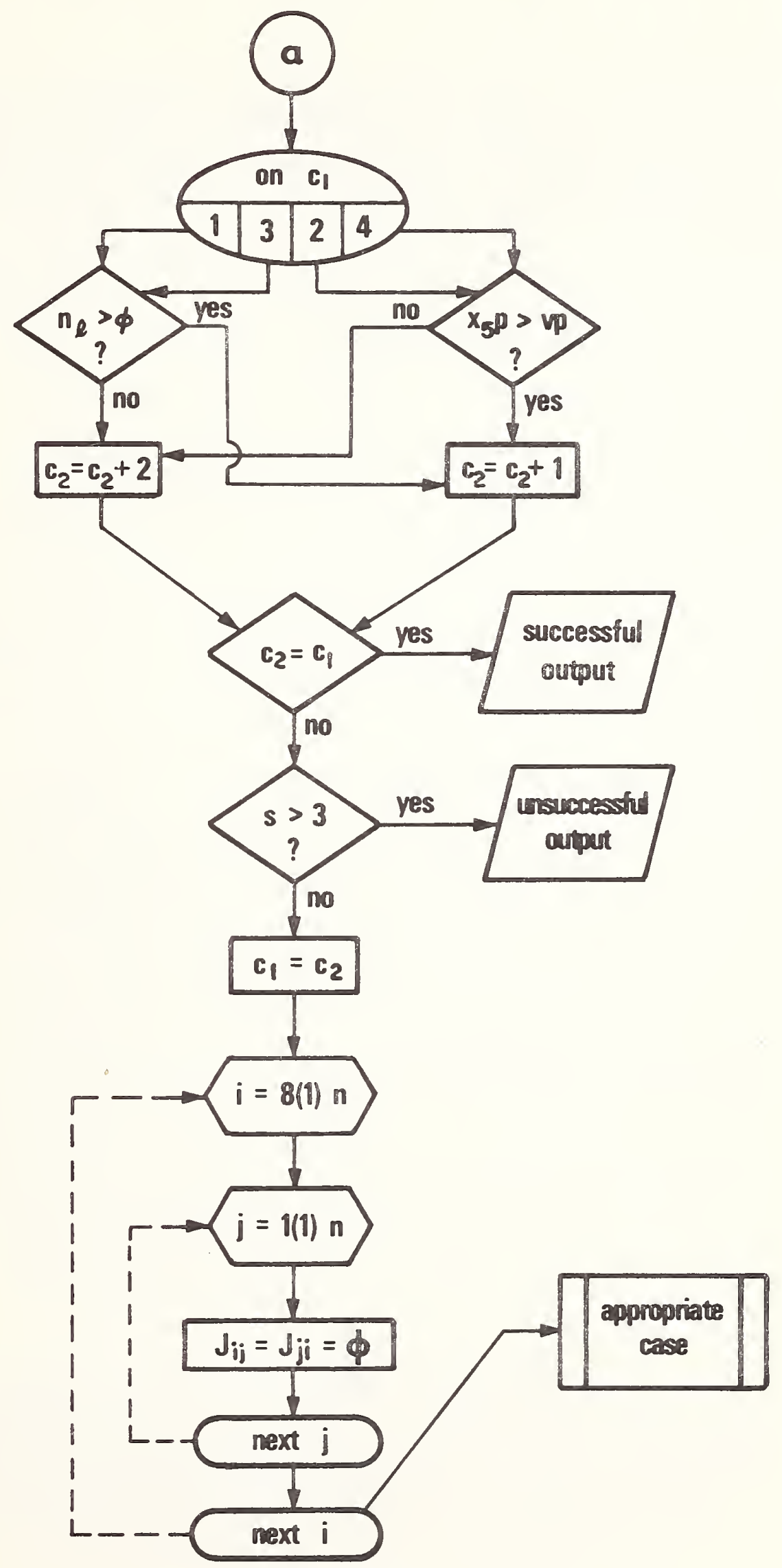

Figure $3 b$ 
Also it is necessary to clear the eigth and ninth rows and columns of the Jacobian preparatory to inserting the appropriate values for the next case. 


\section{DISCUSSION OF THE LISTING}

Appendix 1 gives the list of symbols for the mathematical development in the text and Appendix 2 is for the source program. Wherever possible, the same variable symbol has been used in the text and in the computer program. To avoid cluttering the text, variables used there often have fewer subscripts than the corresponding symbols of the program.

The listing, which is Appendix 3, is given in the full ASCII character set. As stated earlier, it is dependent upon the BASIC compiler used by the Computer Sciences Corporation. * At this writing (Apri1 11, 1978) there is no standard for the BASIC language as there is for FORTRAN [22]. On the other hand almost all BASIC compilers provide reasonably useful diagnostics and internal editing commands so that translation to another compiler should not be a great chore.

Use of the full ASCII set permits use of upper and lower case letters. This has been used to differentiate vectors and matrices. The former, even when the unity dimension is explicitly indicated, are given by lower case letters, as are unsubscripted variables. Matrices are in upper case as are elements of matrices.

Sections are separated by remark statements with leading single quote characters. Some statements are amplified by remarks after a

\footnotetext{
* A particular commerical source is identified in this paper in order to explain the procedure adquately. In no case does such identification imply recommendation or endorsement by the National Bureau of Standards, nor does it imply that the service is necessarily the best for the purpose.
} 
single quote character. Loops have been doubly indented in order to catch the eye, and inner, nested loops are each indented again. The listing is packed, i.e., blanks have been omitted in the program statements except for explanatory matter and output text. The experienced BASIC programmer reads this with ease, and a some storage space is saved. 


\section{INFORMATION FOR USING THE PROGRAM}

Input. After signing on at the terminal the program COLGAS is LOADed and RUN. The following queries will result.

The program first asks whether the problem is to be for constant pressure or volume and whether a short or long printout is desired. The long printout is generally only used when attempting to rerun a nonconverging problem. The answer to these joined questions is therefore generally "p,s" or "v,s". For the long printout "s" is replaced by "l".

The next question concerns the temperature and pressure (or volume). The answers, again separated by a comma, are in kelvins and atmospheres (or liters). Alternatively, degrees Celsius and/or megapascals may be used if the values are preceded by an asterisk without separation by commas or blanks.

The concentrations of the assumed gases are requested next, and the response is to be in mole or volume (decimal) fractions. The answers are typed in the order $\mathrm{CH}_{4}, \mathrm{CO}, \mathrm{CO}_{2}, \mathrm{H}_{2}, \mathrm{H}_{2} \mathrm{O}$ with separating commas. If any of these are not present, zeros must be entered in the appropriate places. If the input concentrations do not satisfy certain requirements, the operator will be requested to try again.

The computer program does not consider problems in which all three elements, $\mathrm{C}, \mathrm{H}$, and $\mathrm{O}$ are not present, i.e., if $\mathrm{CH}_{4}+\mathrm{H}_{2}, \mathrm{H}_{2}+\mathrm{H}_{2} \mathrm{O}$, or $\mathrm{CO}+\mathrm{CO}_{2}$ are used as starting mixtures. In the first two cases only decomposition of the compounds can occur; in the third only disproportionation. (It is assumed that the decomposition of $\mathrm{H}_{2}$ and $\mathrm{CO}$ are negligible.) Such equilibria are calculated by hand directly and 
without iteration. It is also true that a mixture of $\mathrm{CO}_{2}$ and $\mathrm{H}_{2} \mathrm{O}$ does not undergo appreciable reaction.

At this stage, input for the short output is complete. If the long output was chosen the following extra input is requested.

The opportunity to choose the starting case will be next presented. The response is "yes" or "no". If "yes" is typed, the (Arabic) number of the preferred case is requested.

Finally, the operator is to decide if a preferred set of initial estimates is to be used; "yes" or "no". If "yes", the preferred values are requested and these are typed in the same fashion as the assumed gas concentrations. Estimates for only the five gases are to be entered. This is the end of the operator input.

Output. All input data are reprinted as an echo check. After the input gas concentrations have been echoed, the unchosen quantity, volume or pressure, is given. Because the number of moles of gas almost always changes in the final equilibrium, a 11 extensive quantities are quoted on the basis of the number of moles of the assumed gas. Although pressure is not an extensive quantity it too can only be quoted on this basis when a constant volume problem is calculated because the number of moles of gas in the input volume has not been requested.

A long printout gives at this point the assumed case and the results of each iteration until the program terminates successfulty or unsuccessfully. In the latter situation a statement about unsuccessful convergence is followed by the last set of estimates. In any case the mole fractions 
are next and these are followed by the number of moles of gas and the new volume (or pressure).

If liquid water or solid carbon are produced a pertinent statement is made at this point. If the temperature is above the critical value for water, such a statement is made next.

Normally, that is the end of the printout. However, if the run was unsuccessful the independent equilibria will not have been satisfied and statements to this effect will be the last output. 
THE PHASE RULE

For the restricted sets of problems considered here, the phase rule is simple to apply. It is given by equation (48).

$$
F=C-P+2
$$

The number of degrees of freedom, $F$, is the number of independent choices of variables possible with a given system which has $P$ phases and $C$ components. In order to use the traditional symbols for the phase rule, $P$ has been used here, although it has been used before. Because this applies only to this section, confusion should not result. There are three possible phases, gas, liquid water, and solid carbon. The number of components in these problems is equal to the number of chemical elements, three. This simplifies equation (48).

$$
F=5-P
$$

In case IV (see the section on General Statement of the Algorithm) there is only the gas phase, and there must be four variables available for choice. Since two are assumed to be temperature and pressure (or volume), there are two left for concentrations. Thus, if a triangular diagram is used for the concentrations of the elements carbon, hydrogen, and oxygen, the possible elemental concentrations would be represented by an area. See Figure 4. If two atomic compositions are chosen, the third is fixed by the requirement that the percentages add to 100 .

On the other hand for an equilibrium that has either solid carbon or liquid water (but not both) present, there is only one degree of 


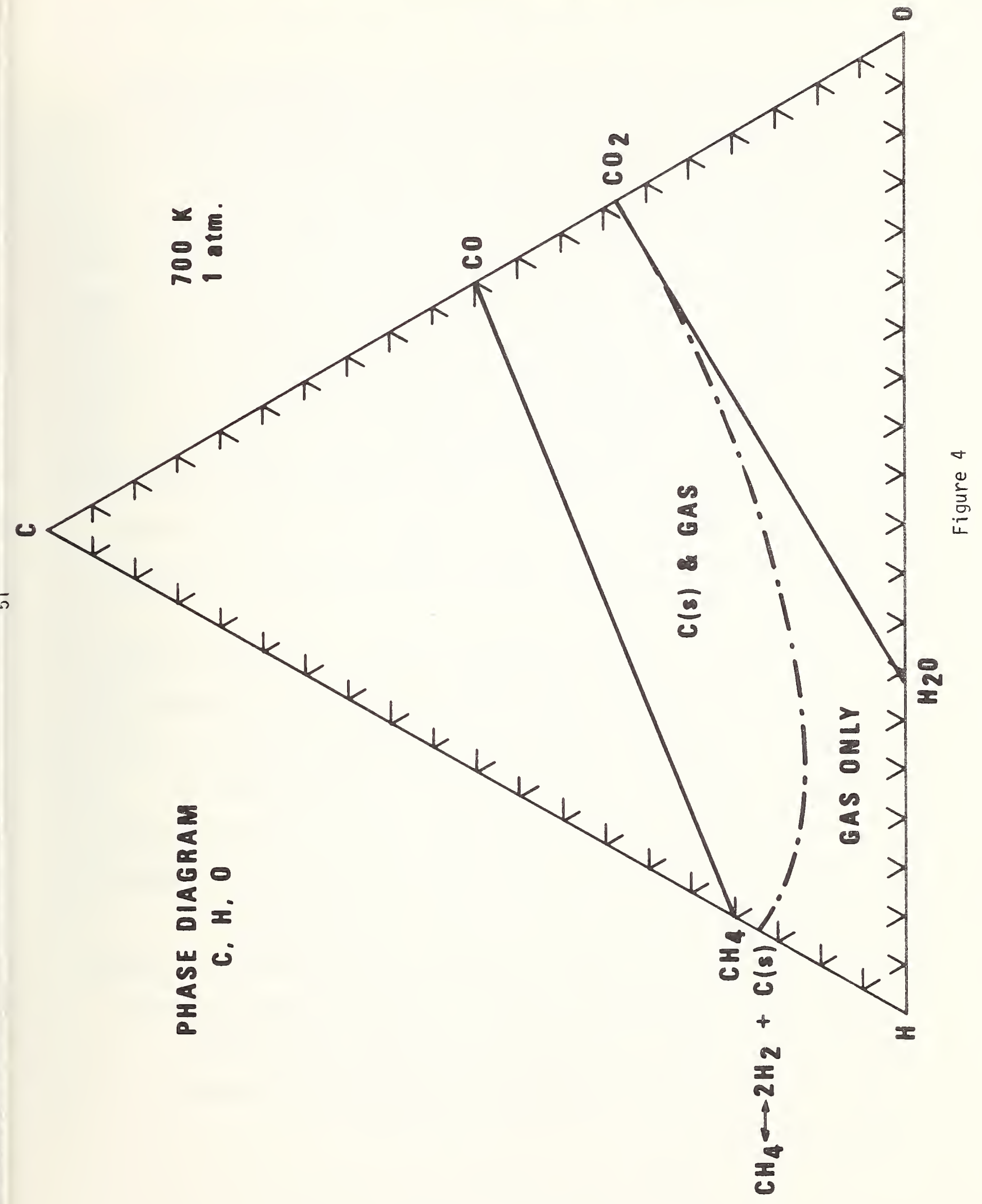


freedom, and this must be represented by a line. Choosing the percentage for just one element fixes both of the others if one condensed phase is present. Also, because the condensed phase always has a fixed composition, the variable composition refers to the gas phase. Referring to Figure 3 , the curved line shows the gas compositions in equilibrium with solid carbon at 700 kelvins and 1 atmosphere. The curve has been drawn by connecting points calculated with COLGAS which turned out to be case II. If a gas mixture contains 15 atomic percent carbon and is in equilibrium with solid carbon the the gas could contain also about 48 atomic percent hydrogen and 37 percent oxygen. Alternatively, it could contain 81 percent hydrogen and 4 percent oxygen. The two possibilities are at the intersections of the 15 percent carbon line with the calculated curve.

A valuable use of the phase diagram in Figure 4 is to show potential carbon precipitation for an assumed test gas mixture. One needs merely to calculate the elemental composition from the compound composition and locate that point on the diagram. If it falls in the area above the curve, carbon will precipitate. Furthermore, extending the line through the apex (for $c=100 \%$ ) and the point to the curve will give the elemental, but, not the compound composition of the gas in equilibrium with the carbon. It should be noted that gas mixtures made from the five postulated substances will have elemental compositions within the region bounded by connecting the compositions of all of the substances with straight lines. The lines should connect $\mathrm{CH}_{4}, \mathrm{CO}, \mathrm{CO}_{2}, \mathrm{H}_{2} \mathrm{O}, \mathrm{H}_{2}$, and return to $\mathrm{CH}_{4}$ in that order. 
Figure 4 represented a situation above the critical temperature of water. Figure 5 illustrates the situation for $500 \mathrm{~K}$ and 50 atmospheres. The diagram is rather more complicated. Although not always indicated, a gas phase is present for all regions of the diagram. There are two invariant points and two regions within which gas compositions will change to one or the other resulting in condensed water and carbon. There are two regions within which the change will result in carbon only, and two more from which only water will condense. Note the two small regions within which no condensation will occur, although five gaseous substances may change their relative amounts. 


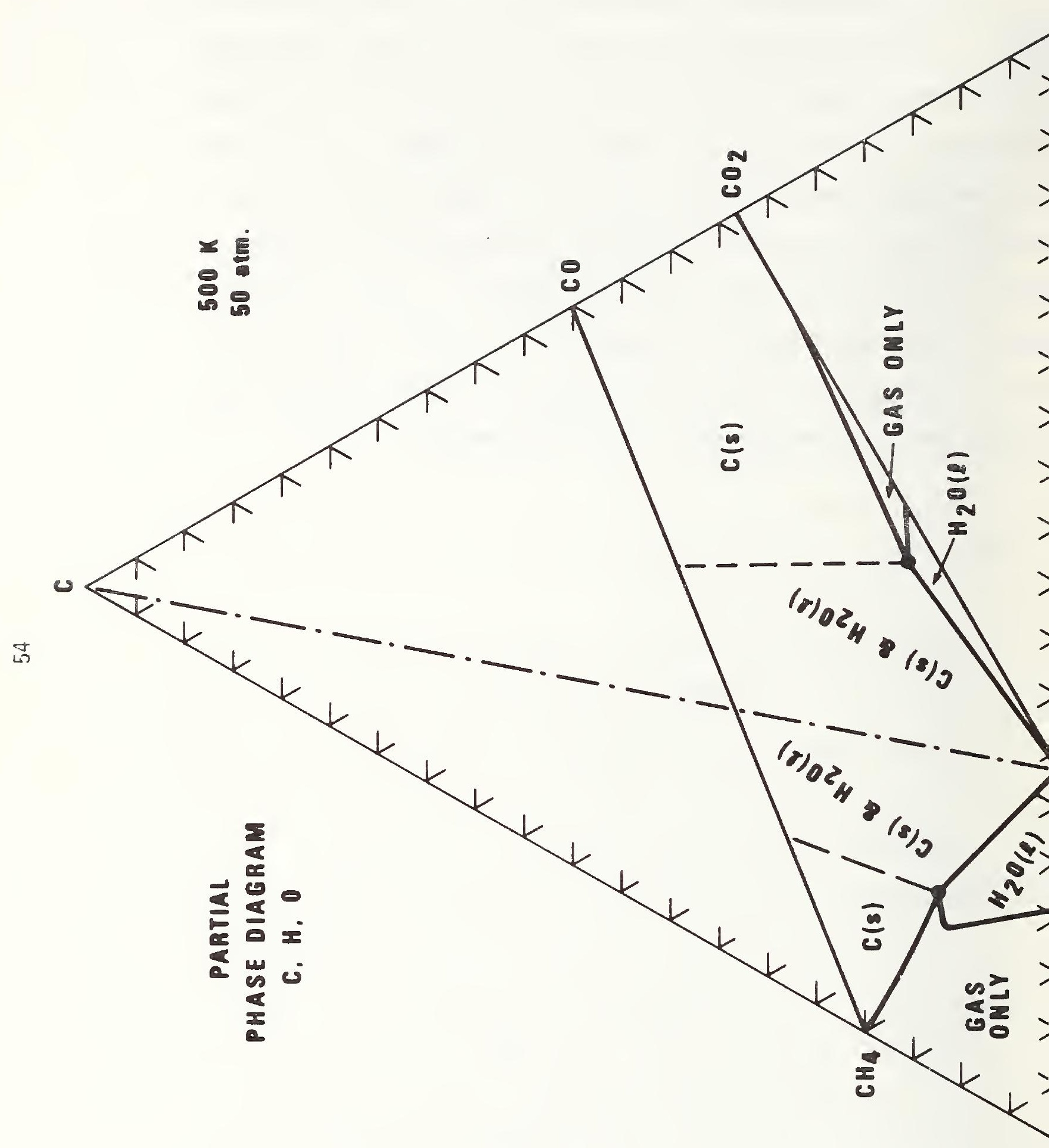


EXAMPLES

Examples $A$ through $D$ are representative of cases I through IV and are successful short printout results. Example B, for $700 \mathrm{~K}$ and 1 atmosphere, corresponds to the conditions for the phase diagram of Figure 3. The original elemental proportions are $.6: 1.6: .8$ and the atomic fractions are $.2, .533$, and .267 . The line extended from the apex through this point on the diagram intersects the curve for solid carbon at approximately $.13, .58$, and .29 . The equilibrium mole fractions for the five substances give for the atomic fractions in the order $C$, $H, 0: .1288, .5809$, and .2904 .

Example $E$ is for a problem which did not converge during the shortprintout run. The last set of estimates suggests that the difficulty involved the amounts of $\mathrm{CO}$ and $\mathrm{CO}_{2}$ which appeared to be continually going negative. Often in a situation of this kind it was found that the initial estimates for such substances were not small enough. Consequently, for the long printout run, example F, initial estimates were chosen equal to the last set from the short run except for the $\mathrm{CO}$ and $\mathrm{CO}_{2}$ which were made smaller. 
Example $A$

colgas $13: 14 \quad 04 / 07 / 78$

Is this a constant pressure $(p)$, or a constant volume (v) problem, and do you want a short (s) or a long (1) printout?p, s

What are the temperature (kelvins) and pressure (atmospheres)?500,100 Temperature $=500 \mathrm{~K}=226.85 \mathrm{C}$

Pressure $=100 \mathrm{~atm}=10.1325 \mathrm{MPa}$

What are the assumed concentrations in mole fractions of the gases in the order: $\mathrm{CH}_{4}, \mathrm{CO}, \mathrm{CO}_{2}, \mathrm{H}_{2}$, and $\mathrm{H}_{2} \mathrm{O}$ ? . $1, .1, .1, .4, .3$

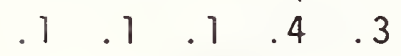

The initial volume $=.410284$ liters per mole of original gas

Gas contains $\mathrm{C}, \mathrm{H}$, and 0 atoms in the proportions $.3,1.8$, and .6

Equilibrium mole fractions in the order $\mathrm{CH}_{4}, \mathrm{CO}, \mathrm{CO}_{2}, \mathrm{H}_{2}, \mathrm{H}_{2} \mathrm{O}$ are:

$\begin{array}{llll}.7301 & .0000 \quad .0077 \quad .0016 \quad .2606\end{array}$

The number of moles of gas $=.2074$ per mole of original gas

The volume $=8.50928 \mathrm{e}-2$ liters per mole of original gas

Solid carbon is present in the amount of .1470 moles per mole of original gas

Liquid water is present in the amount of .5428 mole per moles of original gas

now at end 
Example $B$

colgas $13: 16 \quad 04 / 07 / 78$

Is this a constant pressure $(p)$, or a constant volume ( $v$ ) problem, and do you want a short (s) or a long (1) printout?p,s

What are the temperature (kelvins) and pressure (atmospheres)?700,1

Temperature $=700 \mathrm{~K}=426.85 \mathrm{C}$

Pressure $=1 \mathrm{~atm}=.101325 \mathrm{MPa}$

What are the assumed concentrations in mole fractions of the gases in the order: $\mathrm{CH}_{4}, \mathrm{CO}, \mathrm{CO}_{2}, \mathrm{H}_{2}$, and $\mathrm{H}_{2} \mathrm{O}$ ?.2,.2,.2,.2,.2

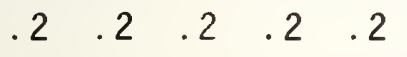

The initial volume $=57.4398$ liters per mole of original gas

Gas contains $\mathrm{C}, \mathrm{H}$, and $\mathrm{O}$ atoms in the proportions $.6,1.6$, and .8

Equilibrium mole fractions in the order $\mathrm{CH}_{4}, \mathrm{CO}, \mathrm{CO}_{2}, \mathrm{H}_{2}, \mathrm{H}_{2} \mathrm{O}$ are: .1693 $.0076 \quad .2344 \quad .1376 \quad .4511$

The number of moles of gas $=.8626$ per mole of original gas

The volume $=49.5486$ liters per mole of original gas

Solid carbon is present in the amount of .2452 moles per mole of original gas

Above the critical temperature for water

now at end 
Example C

colgas $13: 18 \quad 04 / 07 / 78$

Is this a constant pressure $(p)$, or a constant volume ( $v$ ) problem, and do you want a short (s) or a long (1) printout?p, s

What are the temperature (kelvins) and pressure (atmospheres)?500,50

Temperature $=500 \mathrm{~K}=226.85 \mathrm{C}$

Pressure $=50 \mathrm{~atm}=5.06625 \mathrm{MPa}$

What are the assumed concentrations in mole fractions of the gases in the order: $\mathrm{CH}_{4}, \mathrm{CO}, \mathrm{CO}_{2}, \mathrm{H}_{2}$, and $\mathrm{H}_{2} \mathrm{O}$ ?.05,.1,.05,.5,.3

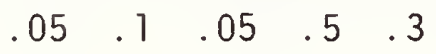

The initial volume $=.820569$ liters per mole of original gas

Gas contains $\mathrm{C}, \mathrm{H}$, and $\mathrm{O}$ atoms in the proportions $.2,1.8$, and .5

Equilibrium mole fractions in the order $\mathrm{CH}_{4}, \mathrm{CO}, \mathrm{CO}_{2}, \mathrm{H}_{2}, \mathrm{H}_{2} \mathrm{O}$ are: .4730 $.0000 \quad .0012 \quad .0047 \quad .5211$

The number of moles of gas $=.4218$ per mole of original gas The volume $=.34611$ liters per mole of original gas

Liquid water is present in the amount of .2792 moles per mole of original gas

now at end 
Example 0

colgas $14: 22 \quad 05 / 03 / 78$

Is this a constant pressure ( $p$ ), or a constant volume ( $v$ ) problem, and do you want a short (s) or a long (1) printout?v, s

What are the temperature (ke1vins) and volume (1iters)?1255, 1.514

Temperature $=1255 \mathrm{~K}=981.85 \mathrm{C}$

Volume $=1.514$ liters

What are the assumed concentrations in mole fractions of the gases in the order: $\mathrm{CH}_{4}, \mathrm{CO}, \mathrm{CO}_{2}, \mathrm{H}_{2}$, and $\mathrm{H}_{2} 0$ ?.05,.18,.12,.25,.4 $\begin{array}{lllll}.05 & .18 & .12 & .25 & .4\end{array}$

The initial pressure $=68.0194 \mathrm{~atm}$ per mole of original gas

Gas contains $\mathrm{C}, \mathrm{H}$, and $\mathrm{O}$ atoms in the proportions $.35,1.5$, and .82

Equilibrium mole fractions in the order $\mathrm{CH}_{4}, \mathrm{CO}, \mathrm{CO}_{2}, \mathrm{H}_{2}, \mathrm{H}_{2} \mathrm{O}$ are:

$\begin{array}{lllll}.0169 & .1902 & .1218 & .3342 & .3368\end{array}$

The number of moles of gas $=1.0640$ per mole of original gas

The pressure $=72.37 \mathrm{~atm}=7.33289 \mathrm{MPa}$ per mole of original gas

Above the critical temperature for water

now at end 
Example $E$

colgas $14: 14 \quad 05 / 03 / 78$

Is this a constant pressure $(p)$, or a constant volume ( $v$ ) problem, and do you want a short (s) or a long (1) printout?p, s

What are the temperature (kelvins) and pressure (atmospheres)?500,50

Temperature $=500 \mathrm{~K}=226.85 \mathrm{C}$

Pressure $=50 \mathrm{~atm}=5.06625 \mathrm{MPa}$

What are the assumed concentrations in mole fractions of the gases in the order: $\mathrm{CH}_{4}, \mathrm{CO}, \mathrm{CO}_{2}, \mathrm{H}_{2}$, and $\mathrm{H}_{2} 0 ? .12,0, .01, .75, .12$ $\begin{array}{lllll}.12 & 0 & .01 & .75 & .12\end{array}$

The initial volume $=.820569$ liters per mole of original gas

Gas contains $\mathrm{C}, \mathrm{H}$, and 0 atoms in the proportions $.13,2.22$, and .14 30 iterations did not converge!

The results at this stage are as follows

Case IV

The last set of estimates is, moles and multipliers:

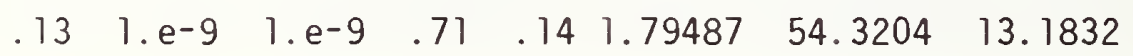

Equilibrium mole fractions in the order $\mathrm{CH}_{4}, \mathrm{CO}, \mathrm{CO}_{2}, \mathrm{H}_{2}, \mathrm{H}_{2} \mathrm{O}$ are: .1327 $.0000 \quad .0000 \quad .7245 \quad .1429$

The number of moles of gas $=.9800$ per mole of original gas

The volume $=.804157$ liters per mole of original gas

Equilibrium constants do not check out

First equilibrium constant $=7.24886 \mathrm{e}-3$ vs. .197184

Second equilibrium constant $=1.20341 \mathrm{e}+10$ vs. 19534.9

Third equilibrium constant $=1.61777 \mathrm{e}-9$ vs. $5.10204 \mathrm{e}-8$ 
Example $\mathrm{F}$

colgas $14: 16 \quad 05 / 03 / 78$

Is this a constant pressure $(p)$, or a constant volume ( $v$ ) problem, and do you want a short (s) or a long (1) printout?p, 1

What are the temperature (kelvins) and pressure (atmospheres) $? 500,50$

Temperature $=500 \mathrm{~K}=226.85 \mathrm{C}$

Pressure $=50 \mathrm{~atm}=5.06625 \mathrm{MPa}$

What are the assumed concentrations in mole fractions of the gases in the order: $\mathrm{CH}_{4}, \mathrm{CO}, \mathrm{CO}_{2}, \mathrm{H}_{2}$, and $\mathrm{H}_{2} 0$ ? . 12,0,.01,.75,. 12

$\begin{array}{lllll}.12 & 0 & .01 & .75 & .12\end{array}$

The initial volume $=.820569$ liters per mole of original gas

Gas contains $\mathrm{C}, \mathrm{H}$, and 0 atoms in the proportions .13,2.22, and .14 Do you want to choose the starting case?no

no

Do you want to provide your own initial estimates?yes

yes

What are they in the same order as above? $.13 \quad 1 . e^{-15} \quad 1 . e^{-14} \quad .71$

.14

$0.13 \quad 1 . e^{-15} \quad 1 . e^{-14} \quad .71 \quad .14$

$\begin{array}{lll}0 & 0 & 0\end{array}$ 


\begin{tabular}{|c|c|c|c|c|c|c|c|c|}
\hline 1 & .13 & $1.00465 e-15$ & $1.01427 e^{-14}$ & .71 & .14 & -1.79487 & 54.3204 & 13.1832 \\
\hline 2 & .13 & $1.023 e^{-15}$ & $1.071053-14$ & .71 & .14 & -1.79487 & 54.3204 & 13.1832 \\
\hline 3 & .13 & $1.0628 e^{-15}$ & $1.1989 e-14$ & .71 & .14 & -1.79487 & 54.3204 & 13.1832 \\
\hline 4 & .13 & $1.12872 \mathrm{e}-15$ & $1.4278 \mathrm{e}-14$ & .71 & .14 & -1.79487 & 54.3204 & 13.1832 \\
\hline 5 & .13 & $1.21986 e^{-15}$ & 1. $78602 e^{-14}$ & .71 & .14 & -1.79487 & 54.3204 & 13.1832 \\
\hline 6 & .13 & $1.32744 e^{-15}$ & $2.28501 e^{-14}$ & .71 & .14 & -1.79487 & 54.3204 & 13.1832 \\
\hline 7 & .13 & $1.43493 e^{-15}$ & $2.89084 e^{-14}$ & .71 & .14 & -1.79487 & 54.3204 & 13.1832 \\
\hline 8 & .13 & $1.52342 e^{-15}$ & $3.50313 e^{-14}$ & .71 & .14 & -1.79487 & 54.3204 & 13.1832 \\
\hline 9 & .13 & $1.58122 e^{-15}$ & $3.98772 e^{-14}$ & .71 & .14 & -1.79487 & 54.3204 & 13.1832 \\
\hline 10 & .13 & $1.60992 e^{-15}$ & 4. $26874 e^{-14}$ & .71 & .14 & -1.79487 & 54.3204 & 13.1832 \\
\hline 11 & .13 & $1.62027 e^{-15}$ & $4.38108 e^{-14}$ & .71 & .14 & -1.79487 & 54.3204 & 13.1832 \\
\hline 12 & .13 & $1.62284 \mathrm{e}-15$ & $4.41047 e^{-14}$ & .71 & .14 & -1.79487 & 54.3204 & 13.1832 \\
\hline 13 & .13 & $1.62325 e^{-15}$ & $4.41521 e^{-14}$ & .71 & .14 & -1.79487 & 54.3204 & 13.1832 \\
\hline 14 & .13 & $1.62328 e^{-15}$ & $4.41564 e^{-14}$ & .71 & .14 & -1.79487 & 54.3204 & 13.1832 \\
\hline 15 & .13 & $1.62329 e-15$ & $4.41565 e^{-14}$ & .71 & .14 & -1.79487 & 54.3204 & 13.1832 \\
\hline
\end{tabular}

Equilibrium mole fractions in the order $\mathrm{CH}_{4}, \mathrm{CO}, \mathrm{CO}_{2}, \mathrm{H}_{2}, \mathrm{H}_{2} \mathrm{O}$ are: $.132653 \quad 1.65641 e^{-15} \quad 4.50576 e^{-14} \quad .72449 \quad .142857$

The number of moles of gas $=1$. per mole of original gas The volume $=.820569$ liters per mole of original gas now at end 


\section{APPENDIX 1}

\section{SYMBOLS - TEXT}

$A$
$C$
$E$
$F$
$F$
$F$
$G$
$G$
$J$
$J$
$L$
$N$
$P$
$P$

R

$\mathrm{T}$

V

$a_{i}$

c

e

$f_{t}$

g

h

$k_{f}$

$k_{i}$

1 th

m

$n_{c}$
$n_{g}^{g}$
$n_{i}$
$p_{i}$
$p_{s}$
$s$
$t$
$x, y$

Helholtz energy of the system

Number of components

Number of gram atoms of element $j$

Number of degrees of freedom

Function actualiy minimized for constant volume problems

Function actually minimized for constant pressure problems

Gibbs energy of the system

Gibbs energy of the chemical elements

Jacobian of the functions set equal to zero for minimization

Inverse of $\mathrm{J}$

Function expressing conservation of element $j$

Number of chemical species

Number of phases (discussion of phase rule oniy)

Pressure of the system

Number of independent chemical reactions (subsection Checking the

Estimates for Stopping Only)

Universal gas constant

Thermodynamic temperature

Volume of the system

Coefficients in the empirical equation for $1 n k_{j}$

Coefficients in the empirical equation for the hatural logarithm of the vapor pressure of water

Number of gram atoms of carbon in the system

Number of chemical elements in the system

value at the $t$-th iteration of the functions set equal to zero

for minimization

Number of gaseous substances

Number of gram atoms of hydrogen in the system

Equilibrium constant of formation of $A_{x} B$

Equilibrium constant of formation of the $\mathrm{y}_{j}$-th substance

Value of weighting factor $k$ for $t$-th trial

Natural logarithm

Maximum exponent of temperature in equations for equilibrium

constants of formation and vapor pressure of water

Number of moles of solid carbon

Total number of moles of gas

Number of moles of the $i$-th substance

Number of gram atoms of oxygen in the system

Partial pressure of substance $i$

Saturated vapor pressure of water.

Total number of substances

Number of trial or interation

Coefficients and subscripts in chemical equation of formation of $A_{x}{ }^{B} y$ 
$x_{t}$

$\Delta G_{f}^{\circ}$

$\Gamma$

$\Gamma_{\mathrm{G}}^{A}$

$\mu_{i}^{j}$

Vector representing the variables being estimated at

iteration number $t$ Gibbs energy of formation of one mole of $A_{x} B_{y}$ with all
substances in the standard states

Function of $A$ which is minimized

Function of $G$ which is minimized

Lagrangian multiplier

Chemical potential, partial molar Gibbs energy of the $i$-th substance 
APPENDIX 2

\section{SYMBOLS - PROGRAM}

$I(i, j)$

$J(i, j)$

$N(i, t 1)$

$a \$$

$a, b, d, e$

$b \$$

$c$

$c \$$

$c(i, i)$

$c(i) \$$

c)

c2

$d \$$

d1

$f(i, 1)$

fnc

fnw

$g$

$g(t 1)$

h

k

$k_{1}, k_{2}, k_{3}$

$k_{4}, k_{5}, k_{6}$

1(i)

n

0

p

$p \$$

$p(t 1)$

p0

$r$

$s$

t

$t \$$

to $t 9$
Inverse of the Jacobian,J

Jacobian

Number of moles of the $i-t h$ substance for the t-th trial

"Yes" or "no" to query about choosing case

Constants used to differentiate functions for the cases

"Yes" or "no" to query about choosing initial estimates

Number of gram atoms of carbon in the system

" $p$ " or "v" for constant pressure or constant volume

problem

Unweighted correction to the $i$-th variable

Case number $i$ as a string variable

Case number during an iteration set

Case number found as a result of iterations

" 7 " or " $s$ " for length of printout desired

Relative difference between saturated vapor pressure

of water and partial pressure of water calculated from

mole fraction found by iteration

The $i$-th function being set equal to zero

Carbon function

Water function

Original number of moles of gas

Number of moles of gas

Number of gram atoms of hydrogen in the system

Weighting factor for applying corrections

Equilibrium constants for the three independent reactions calculated from the logarithms of the equilibrium constants of formation

Equilibrium constants for the three independent reactions calculated from mole fractions found by iteration

Natural logarithm of equilibrium constant of

formation of the $i$-th substance

Size of the pertinent Jacobian

Number of gram atoms of oxygen in the system

Pressure in atmospheres

Pressure as a string variable

Pressure of a constant volume system at the $t$ l-th

trial

Initial pressure in a constant volume system

Universal gas constant

Number of sets of iterations performed

Temperature in kelvins

Temperature as a string variable

Starting and ending indexes for the iteration loop 
Number of an iteration

Square of $t$

Cube of $t$

Fourth power of $t$

Volume

Initial volume in a constant pressure system Mole fraction of the $i$-th gaseous substance 
APPENDIX 3

\section{LISTING}

$100^{\prime}$ colgas WSHorton $9 / 7 / 77$

$110^{\prime}$ Calculates equilibrium composition for the $\mathrm{CH} 4, \mathrm{CO}, \mathrm{CO} 2, \mathrm{H} 2, \mathrm{H} 2 \mathrm{O}$ system

$120^{\prime}$ by minimizing the Gibbs energy for a constant pressure problem or the

$130^{\prime}$ Helmolz energy for a constant volume problem.

$140^{\prime}$

$150^{\prime}$ Initial Statements

$160^{\prime}$

170 width80

180randomize

190dimg (150), I ( 15, 15), J (15, 15), N(15, 150), $P(150)$

200deff $n w=2^{\star} n(6, t 1-1)+n(7, t 1-1)-1(6)$

210deffnc $=c-n(1, t 1-1)-n(2, t 1-1)-n(3, t 1-1)$

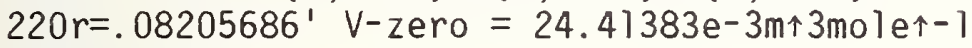

$230 \mathrm{c}(1) \$=" I "$

$240 \mathrm{c}(2) \$=" I I "$

$250 \mathrm{c}(3) \$=" I I$ I"

$260 c(4) \$=" I V "$

$270^{\prime}$

$280^{\prime}$ Input

$290^{\prime}$

300print"Is this a constant pressure ( $p$ ), or a constant volume (v) problem," 310 print"and do you want a short (s) or a long (1) printout";

320 inputc $\$, d \$$

330 print"What are the temperature (kelvins) and";

340 ifc $\$=" p$ "orc $\$=" p$ "then 380

350print" volume (1 iters)";

360 inputt $\$, v$

370 goto 400

380print" pressure (atmospheres)";

390 inputt $\$, p \$$

400 ift $\$(1,1)=11 *$ "then 430

$410 t=\operatorname{val}(t \$)$

420 goto 440

$430 t=\operatorname{val}(t \$(2))+273.15$

440 print"Temperature $=" t ; " k=" ; t-273.15 ; " C "$

450 i $c \$=" p$ " orc $\$=" p$ "then 480

460print"volume ="v;"1 iters"

470 goto530

480 ifp $\$(1,1)=11 *$ "then 510

$490 p=\operatorname{val}(p \$)$

500 goto 520

$510 p=\operatorname{val}(p \$(2)) / .10325$

520print"Pressure ="p;"atm ="; $p^{\star} 0.101325 ; " M P a^{\prime \prime}$

530 print

540print"What are the assumed concentrations in mole fractions of the gases" 
550print"in the order: $\mathrm{CH} 4, \mathrm{CO}, \mathrm{CO} 2, \mathrm{H} 2$, and $\mathrm{H} 2 \mathrm{O}^{\prime \prime}$;

560 inputn $(1,0), n(2,0), n(3,0), n(4,0), n(5,0)$

$570 g=g(0)=n(1,0)+n(2,0)+n(3,0)+n(4,0)+n(5,0)$

$580 c=n(1,0)+n(2,0)+n(3,0)$

$590 h=4^{\star} n(1,0)+2^{\star} n(4,0)+2^{\star} n(5,0)$

$6000=n(2,0)+2^{*} n(3,0)+n(5,0)$

610 if $c \$<>0$ andh $\$<>0$ ando $\$<>0$ then 650

620 print"It is necessary to have compounds containing carbon, oxygen,"

630 print"and hydrogen. Please try again."

640 goto 540

650 if $n(1,0)+n(2,0)+n(4,0) \$<>0$ then680

660 print"Carbon dioxide and water alone do not react significantly"

670 goto $3850^{\prime}$ print, end

680 fori=1 to 5

$690 \operatorname{printn}(i, 0)$;

700 ifn $(i, 0)<>0$ then 720

$710 n(i, 0)=1 e^{-7}$

720nexti

730 print

740 print

750 ifc $\$=" p$ "orc $\$=" p^{\prime \prime}$ then 810

$760 \mathrm{a}=0$

$770 p=p 0=r^{\star} t / v$

$780 p(0)=g(0)^{\star} p 0^{\prime}$ Initial estimate of pressure

790 print"The initial pressure $=" p(0)$; "atm per mole of original gas"

800 goto 840

$810 \mathrm{a}=1$

$820 v 0=r^{*} t / p^{\prime} \quad$ Initial volume

830 print"The initial volume ="v0;"liters per mole of original gas"

840 print

850 print"Gas contains C, H, and 0 atoms in the proportions"c;", "h;", and"o 860 ifd $\$=" s$ " ord $\$="$ "S"then970

870 print"Do you want to choose the starting case";

880 inputa $\$$

$890 p r i n t a \$$

900 ifa $\$="$ no" then 960

910 print"What case number";

920 inputc 1

930print"Case number"c1

940print

950 goto 990

960 print

$970 \mathrm{Cl}=0^{\prime}$ Causes bypass of line 1530

980 ifd $\$=" s$ "ord $\$=" S "$ then 1180

990print"Do you want to provide your own initial estimates";

1000 inputb $\$$

1010 printb\$

1020print

1030 i fb $\$=$ "yes" then 1050

1040 goto 1090 
1050print"What are they in the same order as above";

1060 inputn $(1,0), n(2,0), n(3,0), n(4,0), n(5,0)$

1070 printn $(1,0) ; n(2,0) ; n(3,0) ; n(4,0) ; n(5,0)$

1080 print

1090 print" $0 "$;

$1100 \mathrm{~g}(0)=0$

1110 for $i=1$ to 5

$1120 \operatorname{printn}(i, 0)$;

1130 ifn $(i, 0)<>0$ then 1150

$1140 n(i, t i)=10$ o $\left(-7-i n t\left(4^{*}\right.\right.$ rnd $\left.)\right)$

$1150 \quad g(0)=g(0)+n(i, 0)$

1160 nexti

1770 print

$1180 n(6,0)=n(7,0)=n(8,0)=n(9,0)=0$

$1190^{\prime}$

$1200^{\prime}$ Thermodynamic Data

$1210^{\prime}$

$1220 \mathrm{t} 2=\mathrm{t}^{*} \mathrm{t}$

$1230 t 3=t^{\star} t 2$

$1240 \mathrm{t} 4=\mathrm{t} 2^{\star} \mathrm{t} 2$

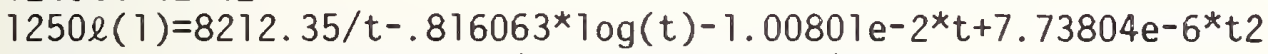

$1260 \ell(1)=\ell(1)-3.06981 e-9^{*} t 3+5.08552 e^{-1} 3^{*} t 4$

$1270 \ell(2)=13632.3 / t+1.8055^{*} \log (t)-.0023936^{*} t+3.72836 e^{-7 *} t 2$

$1280 \ell(3)=47326.7 / t+.0777872^{\star} \log (t)-2.80706 e^{-} 4^{\star} t+3.48747 e^{-8 *} t 2$

$1290 \ell(4)=0$

$1300 \ell(5)=28786.6 / t-.697311^{*} \log (t)-.00145957^{*} t+8.3769 e^{-7 *} t 2-1.80285 e-10^{*} t 3$

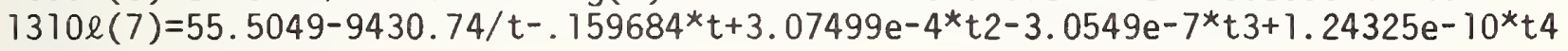

$1320 \ell(6)=1(5)-1(7)$

$1330 \mathrm{k} 1=\exp (\ell(2)+\ell(5)-\ell(3)-\ell(4))$

$1340 \mathrm{k} 2=\exp \left(\ell(1)+\ell(5)-\ell(2)-3^{*} \ell(4)\right)$

$1350 \mathrm{k} 3=\exp \left(2^{*} \ell(2)-\ell(3)\right)$

1360 for $i=1$ to 5

$1370 m(i)=\log (p)-\ell(i)$

1380 nexti

$1390^{\prime}$

$1400^{\prime}$ Assign max. size and constant elements of basic Jacobian

$1410^{\prime}$

$1420 n=9$

1430 mat $J=\operatorname{zer}(n, n)$

$1440 \mathrm{~J}(2,7)=\mathrm{J}(7,2)=\mathrm{J}(5,7)=\mathrm{J}(7,5)=1$

$1450 \mathrm{~J}(3,7)=\mathrm{J}(7,3)=\mathrm{J}(4,6)=\mathrm{J}(6,4)=\mathrm{J}(5,6)=\mathrm{J}(6,5)=2$

$1460 \mathrm{~J}(1,6)=\mathrm{J}(6,1)=4$

$1470^{\prime}$

$1480^{\prime}$ Assign constants for first set of iterations

$1490^{\prime}$

$1500 s=0$

1510 to $=1$

1520 t9 $=30$

1530 onc l goto $1630,1790,1920,2080$

$1540^{\prime}$ 
$1550^{\prime}$ Test for possibility of liquid water"

$1560^{\prime}$

1570 if $t<647$. 3andp $>\exp (\ell(7))$ then 1600

$1580 \mathrm{c} 1=2$

1590 goto 1790

$1600 \mathrm{c} 7=4$

1610 goto 2080

$1620^{\circ}$

$1630^{\prime}$ Case I

$1640^{\prime}$

1650 ifs $>0$ then 1680

1660 if $d \$=" s$ "ord $\$="$ " $s$ "then 1680

1670 printn $(6,0) ; n(7,0) ; n(8,0)$

$1680 \mathrm{~b}=\mathrm{e}=0$

$1690 \mathrm{~d}=1$

$1700 n=8$

$1710 J(6,8)=J(8,6)=2$

$1720 \mathrm{~J}(7,8)=\mathrm{J}(8,7)=1$

1730 ifd $\$=" s^{1}$ ord $\$="$ " $S$ "then 1770

1740 print

1750print"Case I"

1760 print

1770goto2220' iterate

$1780^{\circ}$

$1790^{\prime}$ Case II

$1800^{\prime}$

1810 ifs $>0$ then 1840

1820 ifd $\$=$ " $s$ "ord $\$=$ " $\$$ " then 1840

1830 printn $(6,0) ; n(7,0)$

$1840 \mathrm{~b}=\mathrm{d}=\mathrm{e}=0$

$1850 n=7$

1860 ifd $\$=1$ "s"ord $\$="$ "S" then 1900

1870print

1880print"Case II"

1890 print

1900 goto $2220^{\prime}$ iterate

$1910^{\prime}$

$1920^{\prime}$ Case III

$1930^{\prime}$

1940 ifs $>0$ then 1970

1950 ifd $\$="$ " $s$ "ord $\$="$ " $S$ " then 1970

1960 printn $(6,0) ; n(7,0) ; n(8,0) ; n(9,0)$

$1970 b=d=1$

$1980 \mathrm{e}=n=9$

$1990 J(6,8)=J(8,6)=2$

$2000 J(7,8)=J(8,7)=1$

$2010 J(1,9)=J(9,1)=J(2,9)=J(9,2)=J(3,9)=J(9,3)=1$

2020 i fd $\$=" s$ " ord $\$="$ " $s$ " then 2060

2030print

2040print"Case III" 
2050 print

2060 goto2220' iterate

$2070^{\prime}$

$2080^{\prime}$ Case IV

$2090^{\prime}$

2100 ifs $>0$ then 2130

2110 ifd $\$=" s$ "ord $\$=$ "S"then2130

$2120 p r i n t n(6,0) ; n(7,0) ; n(8,0)$

$2130 \mathrm{~b}=1$

$2140 \mathrm{~d}=0$

$2150 \mathrm{e}=\mathrm{n}=8$

$2160 \mathrm{~J}(1,8)=\mathrm{J}(8,1)=\mathrm{J}(2,8)=\mathrm{J}(8,2)=\mathrm{J}(3,8)=\mathrm{J}(8,3)=1$

2170 i $\mathrm{fd} \$=$ " $\mathrm{s}$ "ord $\$=$ "S" then 2220

2180print

2190print"Case IV"

2200 print

$2210^{\prime}$

$2220^{\prime}$ Newton-Raphson Iterations

$2230^{\prime}$

2240 fort $1=$ t 0 tot 9

$\left.\left.2250 \quad f(1,1)=\log (n(1, t]-1))-a^{*} \log (g(t)-1)\right)+4^{*} n(6, t]-1\right)+b^{*} n(e, t 1-1)+m(1)$

$2260 f(2,1)=\log (n(2, t 1-1))-a^{*} \log (g(t 1-1))+n(7, t i-1)+b^{*} n(e, t i-1)+m(2)$

$\left.\left.2270 f(3,1)=\log (n(3, t]-1))-a^{*} \log (g(t)-1)\right)+2^{*} n(7, t]-1\right)+b^{*} n(e, t 7-1)+m(3)$

$2280 \quad f(4,1)=\log (n(4, t 1-1))-a^{*} \log (g(t 1-1))+2^{*} n(6, t 1-1)+m(4)$

$2290 \quad f(5,1)=\log (n(5, t 1-1))-a^{*} \log (g(t 1-1))+2^{*} n(6, t 1-1)+n(7, t 1-1)+m(5)$

$2300 \quad f(6,1)=4^{*} n(1, t 1-1)+2^{*} n(4, t 1-1)+2^{*} n(5, t 1-1)+d^{*} 2^{*} n(8, t 1-1)-h$

$2310 f(7,1)=n(2, t i-1)+2^{*} n(3, t 1-1)+n(5, t i-1)+d^{*} n(8, t 1-1)-0$

2320 onclgoto $2330,2390,2350,2380$

$2330 f(8,7)=f n w$

2340 goto 2390

$2350 \quad f(8,1)=f n w$

$2360 f(9,1)=-f n c$

2370 goto2390

$2380 f(8,1)=-f n c$

2390 if $\$=" p$ "orc $\$=$ " $p$ "then 2440

2400 for $i=1$ to 5

$2410 \quad J(i, i)=1 / n(i, t 1-i)$

2420 nexti

2430 goto 2520

2440 for $i=1$ to 5

2450 for $j=7$ to 5

2460

2470

2480

2490

2500

2510

2520

2530

2540

if $i=j$ then 2490

$J(i, J)=-1 / g(t]-1)$ goto 2500

$J(i, i)=1 / n(i, t l-1)-1 / g(t-1-1)$

nextj

next $i$

$\operatorname{matI}(n, n)=\operatorname{inv}(J(n, n))$

$\operatorname{matc}(n, 1)=I(n, n)^{*} f(n, 1)$

if $d \$=" s$ "ord $\$=" s$ " then 2560 


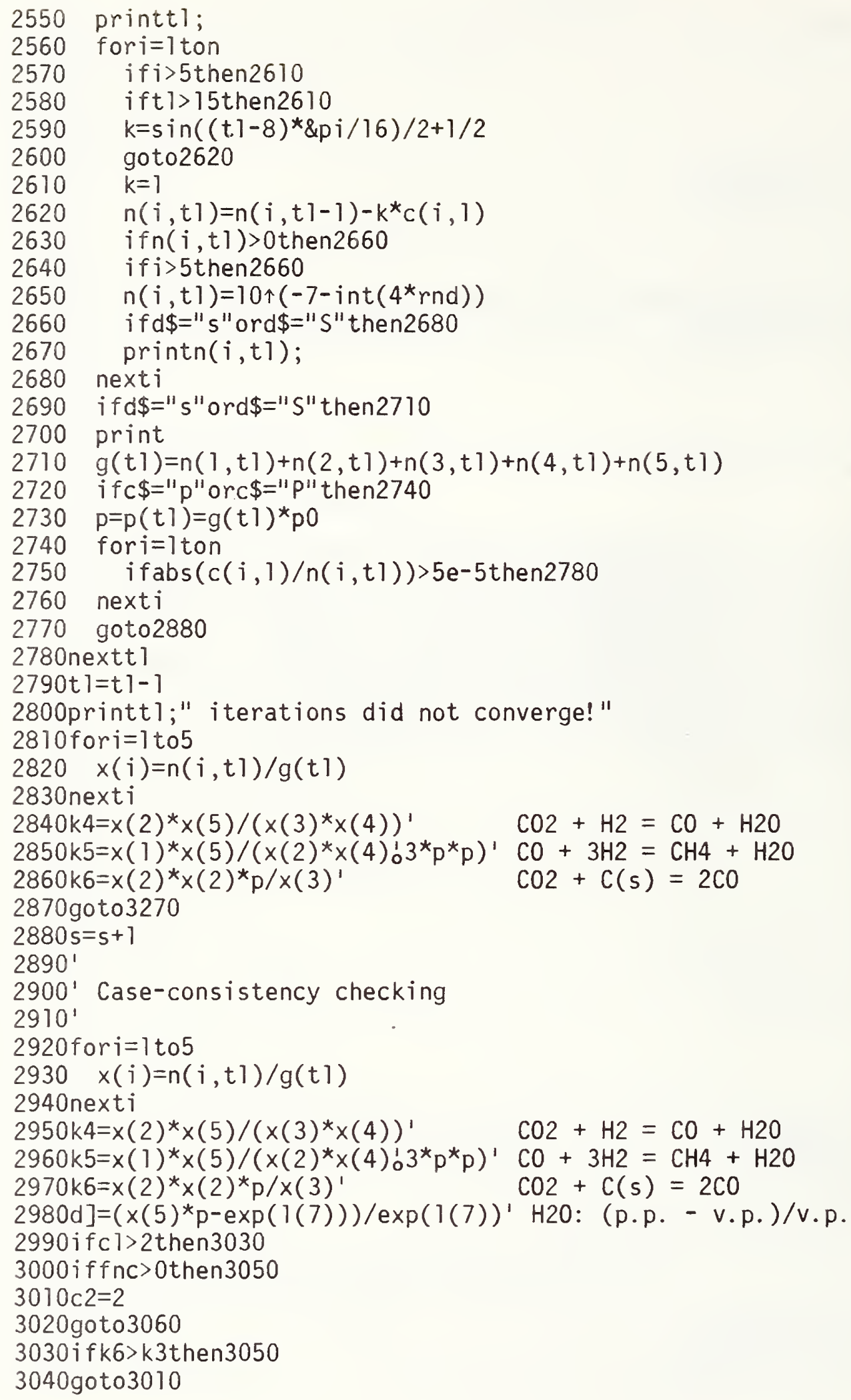


$3050 \mathrm{c} 2=0$

3060 oncl goto $3070,3090,3070,3090$

3070 if $n(8, t 1)>0$ then 3120

3080 goto 3100

3090 if $x(5){ }^{*} p>\exp (\ell(7))$ then 3120

$3100 \mathrm{c} 2=\mathrm{c} 2+2$

3110 goto 3130

$3120 \mathrm{c} 2=\mathrm{c} 2+1$

3130 ifc $2=c 1$ then $3340^{\prime}$ successful exit

3140 ifs $>3$ then $3250^{\prime}$ unsuccessful exit; four inconsistent sets of iterations

$3150 \mathrm{c} 1=\mathrm{c} 2$

3160 for $i=8$ ton

3170 for $j=1$ ton

$3180 \quad J(i, J)=J(J, i)=0$

3190 nextj

3200 nexti

3210 onc lgoto $1630,1790,1920,2080$

$3220^{\prime}$

$3230^{\prime}$ Output

$3240^{\prime}$

3250 print"Could not determine correct case with four sets of iterations"

3260 print

3270 print"The results at this stage are as follows"

3280print"Case "c(c1)\$

3290print"The last set of estimates is, moles and multipliers:"

3300 for $i=1$ ton

$3310 \operatorname{printn}(i, t])$;

3320nexti

3330 print

3340 print

3350 print"Equilibrium mole fractions in the order $\mathrm{CH} 4, \mathrm{CO}, \mathrm{CO}$, H2, H2O are:" 3360 for $i=1$ to 5

3370 ifd $\$=" \ell$ "ord $\$=" L$ "then 3400

3380 printusing".\#\#\#",$x(i)$;

3390 goto3410

3400 printx(i);

3410 nexti

3420 print

3430 print

3440 i fd $\$=" 1$ "ord $\$=$ "L"then3470

3450 printusing"The number of moles of gas = \#.\#\#\# per mole of original gas",g(t

1) $/ \mathrm{g}$

3460 goto 3480

3470 print"The number of moles of gas $=" g(t 1) / g$;"per mole of original gas"

3480 if $c \$=" p$ "orc $\$=" p$ "then 3510

3490print"The pressure $={ }^{\prime \prime} \mathrm{g}(\mathrm{t} 1)^{*} \mathrm{p} 0 / \mathrm{g} ;{ }^{\prime \prime a t m}=" .101325^{*} \mathrm{~g}(\mathrm{t} 1)^{*} \mathrm{p} 0 / \mathrm{g}$;

"MPa per mole of original gas"

3500 goto 3520

3510 print"The volume $=" \mathrm{~g}(\mathrm{t} 1)^{\star} \mathrm{v} 0 / \mathrm{g} ; "$ liters per mole of original gas"

3520 print 
3530 oncgoto $3540,3540,3590,3630$

3540 ifd $\$="$ " $\ell$ "ord $\$=" L "$ then3570

3550printusing"Solid carbon is present in the amount of \#.\#\#\# moles per mole of original gas", fnc/g

3560 goto 3580

3570print"Solid carbon is present in the amount of "fnc/g;"moles per mole of original gas"

3580 i $\mathrm{fCl}=2$ then 3630

3590 ifd $\$=" 2$ " or $d \$=" L "$ then 3620

3600 printusing"Liquid water is present in the amount of \#.\#\#\#\#oles per mole of original gas", $n(8, t 1) / g(0)$

3610 goto 3630

3620 print"Liquid water is present in the amount of " $n(8, t 1) / g ; "$ moles

per mole of original gas"

3630 print

3640 ifabs $(k 4-k 1) / k 1>1$ e-4then 3710

3650 ifabs $(k 5-k 2) / k 2>1$ e-4then 3710

3650 oncl goto $3670,3670,3690,3690$

3670 if abs $(k 6-k 3) / k 3>$ le-4then 3710

3680 goto 3750

3690 if $(k 3-k 3) / k 3>1 e-4$ then 3710

3700 goto 3750

$3710 p$ rint"Equilibrium constants do not check out"

3720print"First equilibrium constant =" k1;"vs. "k4

3730print"Second equilibrium constant ="k2;"vs. "k5

3740print"Third equilibrium constant ="k3;"vs. "k6

3750 ift $>647$. 3 then 3840

3760 onc lgoto $3770,3790,3770,3790$

3770 ifabs $(d 1)>5 e-5$ then 3800

3780 goto 3850

3790 ifd $<<5 e-5$ then 3850

3800 print"Relationship of $\mathrm{H} 20$ partial pressure and vapor pressure is wrong"

3810 print"Vapor pressure of water $=" \exp (\ell(7))$

3820 print"Partial pressure of water $=" p^{\star} \times(5)$

3830 goto 3850

3840 print"Above the critical temperature for water"

3850 print

$3860^{\prime}$ end 


\section{REFERENCES}

[1] Glasstone, S., "Thermodynamics for Chemists," D. van Nostrand Company Inc., New York, 1947.

[2] Stanczyk, N. H., "Research Support on Materials for Coal Conversion Process Task II," Fourth Quarterly Report, JulySeptember 1977, ERDA Contract E(49-18)-2219, Tuscaloosa Metallurgical Research Center, Bureau of Mines.

[3] McGlashan, M. L., Ed., "Manual of Symbols and Terminology for Physiochemical Quantities and Units," International Union of Pure and Applied Chemistry, Butterworths, London, 1970.

[4] Hamming, R. W., "Introduction to Applied Numerical Analysis," McGraw Hi11 Book Company, New York, 1971, p 238.

[5] Krieger, F. J. and White, W. B., J. Chem. Phys., 16, 358-60 (1948).

[6] Sokolnikoff, I. S., Advanced Calculus, McGraw Hill Book Company, New York, 1939, p 327-34.

[7] Scarborough, J. B., Numerical Mathematics and Analysis, 5th ed., John Hopkins Press, Baltimore, 1962, p 213-17.

[8] Gordon, S. and MCBride, B. J., Computer Program for Calculation of Complex Chemical Equilibrium Compositions, Rocket Performance, Incident and Reflected Shocks, and Chapman-Jouget Detonations, NASA SP-273, NTIS No. N71-37775, 1971, p 245.

[9] Van Zeggeren, F. and Storey, S. H., The Computation of Chemical Equilibria, Cambridge University Press, Cambridge, 1970.

[10] Brinkley, S. R., J. Chem. Phys., 15, 107-10 (1947). 
[11] White, W. B., Johnson, S. M. and Dantzig, G. B., J. Chem. Phys. 28, $751-5(1958)$.

[12] Schaefer, A. 0., Samans, C. H., Howes, M. A., Bhattacharyga, S., Bangs, E. R., Hil1, V. L. and Chang, F. C., Annual Report for 1975, No. FE 1784-12, Metals Properties Counci1, Inc., January 20, 1976.

[13] Zeleznik, F. J. and Gordon, S., Ind. Eng. Chem. 60 27-57 (1968).

[14] Spencer, F. E. and Orning, A. A., An Algorithm for Calculating Multiphase Chemical Equilibrium, Bureau of Mines Report RI 7786, 1973, p 42.

[15] Stul1, D. R. and Prophet, H., JANAF Thermochemical Tables, 2nd ed., Nat. Bur. Stand. Pub1. NSRDS-NBS37, U.S. Gov't. P.0. Cat. No. C $13.48: 37$.

[16] Jennings, A., Matrix Computation for Engineers and Scientists, John Wiley and Sons, New York, 1977.

[17] Householder, A. S., The Theory of Matrices in Numerical Analysis, Dover, p $10,1975$.

[18] Klein, M., Practical Treatment of Coupled Gas Equilibrium, Chapter 7 in Physical Chemistry: An Advanced Treatise in Eleven Volumes, Ed. H. Eyring, W. Jost and D. Henderson, Academic Press, New York, Volume I, Thermodynamics, 1971.

[19] Baron, R. E., Porter, J. H. and Hammond, O. H., Jr., Chemical Equilibria in Carbon-Hydrogen-0xygen Systems, MIT Press, (Cambridge USA), 1976.

[20] Hogben, D., Peavy, S. T. and Varner, R. N., OMNITAB II Users Reference Manual, Nat. Bur. Stand. Tech. Note 552, October 1971. 
[21] Wampler, R. H., J. Am. Stat. Assoc., 65, 549-65 (1970).

[22] American Standard FORTRAN, X3.9-1966, American Standards Association, New York, March 7, 1966, p 38.

[23] Brinckley, S. R., Jr., J. Chem. Phys. 14, 563-4 (1946).

[24] Schmidt, E., Properties of Water and Steam in SI-Units, SpringerVerlag New York, Inc., New York, 1969. 



\section{FEDERAL INFORMATION PROCESSING STANDARD SOFTWARE SUMMARY}

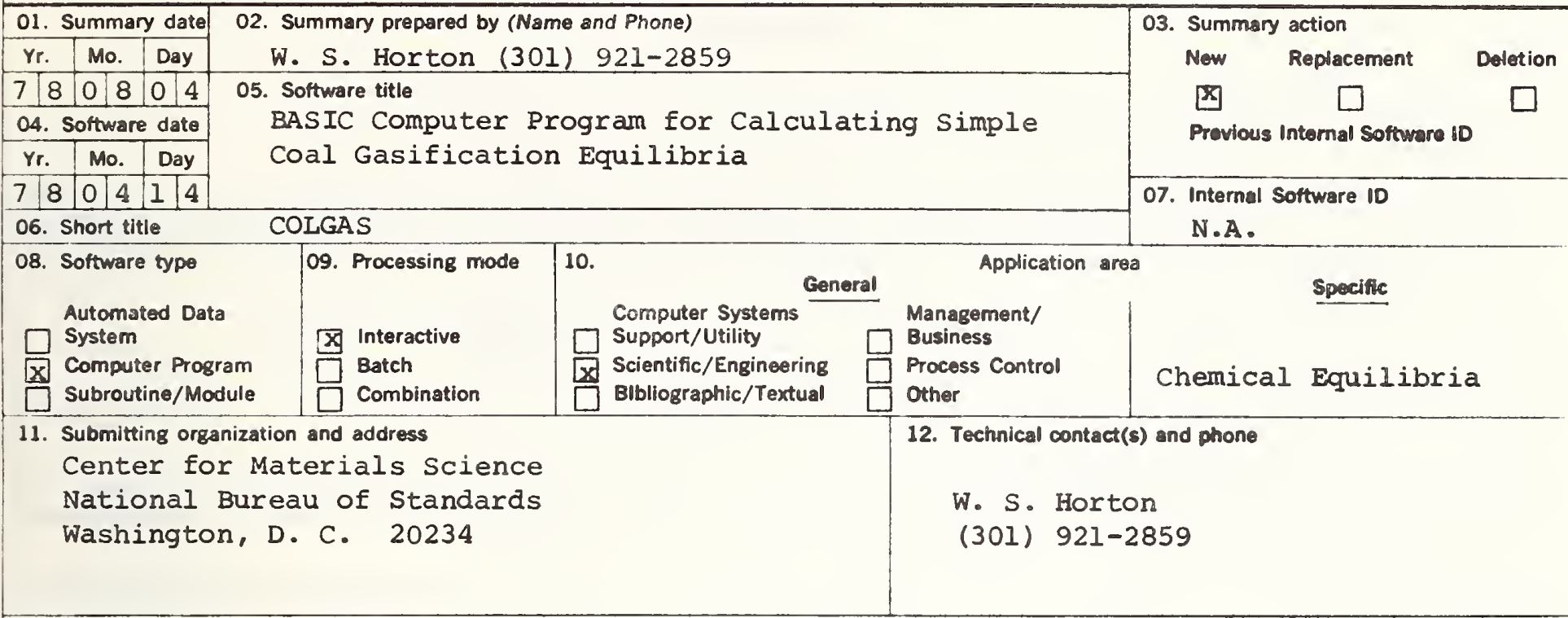

13. Narrative

COLGAS calculates the concentrations of gases and amounts of sölid carbon and/or liquid water at equilibrium for constituents found in coal gasification plants. The gases are restricted to methane, carbon monoxide, carbon dioxide, hydrogen, and water and are considered to be ideal. Minimization of Gibbs energy is achieved by setting partial derivatives equal to zero and solving the resulting nonłinear equations by the NewtonRaphson technique.

14. Keywords

BASIC; carbon; carbon dioxide; carbon monoxide; coal gasification; CoLGAs; hydrogen; interactive computer program; methane; minization of Gibbs energy; phase rule; simultaneous chemical equilibria; water

15. Computer manuf'r and model $\quad$ 16. Computer operating system UNIVAC 1108 CSTS-Release 18

17. Programing language(s) BASIC

21. Disk/Drum units

None
18. Number of source program state. monts 377

22. Terminals

one, time-sharing, 110 or 300 baud

23. Other operational requirements

None

24. Software availability

Avaliable

$\square$
Limited

$\square$
In-house only

区
25. Documentation availability

Available Inadequate

区
In-house only

26. FOR SUBMITTING ORGANIZATION USE

Documentation available from NTIS or the author: W. S. Horton, "An AIgorithm and BASIC Computer Program for Calculating Simple Coal Gasification Equilibria", NBS-IR $78-1509$ 


\section{INSTRUCTIONS}

01. Summary Date. Enter date summary prepared. Use Year, Month, Day format: YMMDD.

02. Summary Prepared By. Enter name and phone number (including area code) of individual who prepared this summary.

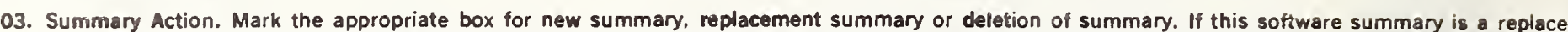

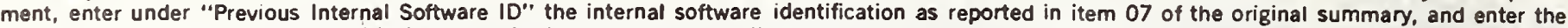

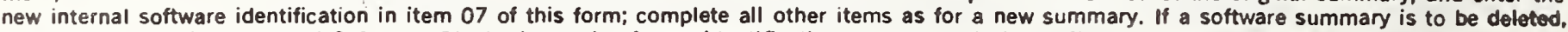

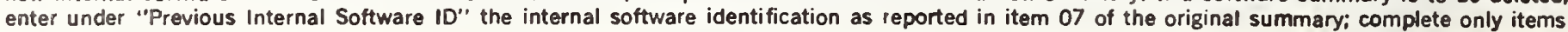
$01,02,03$ and 11 on this form.

04. Sofhware Date. Enter date software was completed or last updated. Use Year, Month, Day format: YYMMDD.

05. Software Title. Make title as descriptive as possible.

06. Short Title. (Optional) Enter commonly used abbreviation or acronym which identifies the software.

07. Intemal Software ID. Enter a unique Identification number or code.

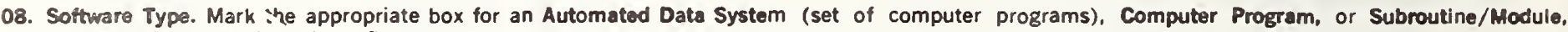
whichever best describes the software.

09. Processing Mode. Mark the appropriate box for an Interactive, Batch, or Combinatlon mode, whichever best describes the software.

10. Appllcation Area.

Goneral: Mark the appropriate box which best describes the general area of application from among:

Computer Systems Support/Utility Process Control

Management/Business Bibliographic/Textual

Scientific/Engineering Other

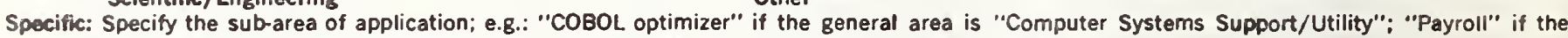
general area is "Management/Business": etc. Elaborate here if the general area is "Other."

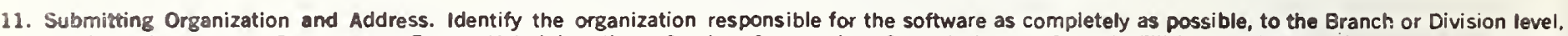

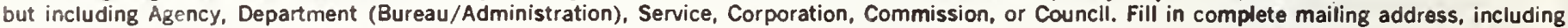
mail code, street address, city, state, and ZIP code.

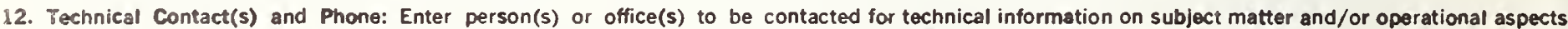
of software. Include telephone area code. Provide organization name and malling address, if different from that In item 11.

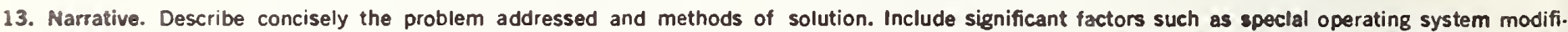

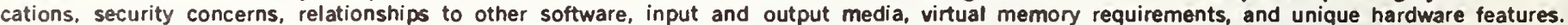
Cite roferences, if appropriate.

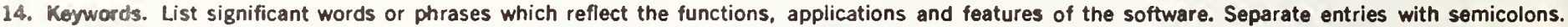

15. Computer Manufacturer and Model. Identify mainframe computer(s) on which software is operational.

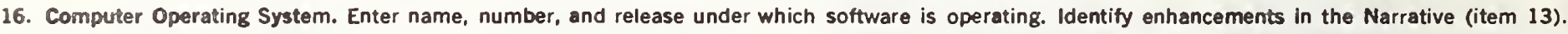

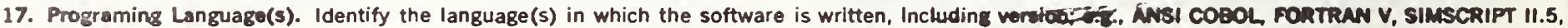
SLEUTH II.

18. Number of Source Program Statements. "Include statements in this software, separate macros, called surnutines, me.

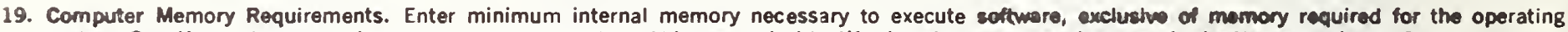
system. Specify words, bytes, characters, etc., and number of bits per unit. Identlfy virtual memory regulrements in the Narrative (item 13).

20. Tape Drives. Identify number needed to operate software. Specify, if critical, manufacturer, model, tracks, recording denslty, etc.

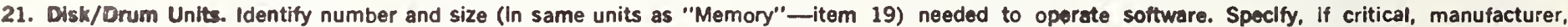
model, etc.

22. Terminals. Identify number of terminals required. Specify, if critical, type, speed, character set, screen/line slze, etc.

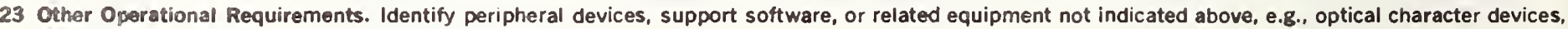
facsimile, computer-output microfilm, graphic plotters.

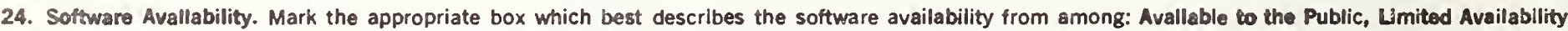

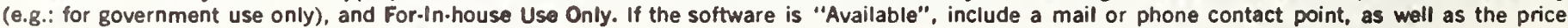
and form in which the software is available, if possible.

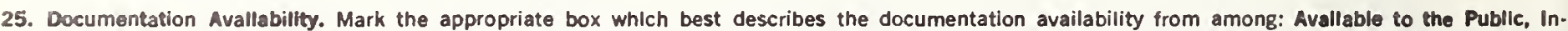

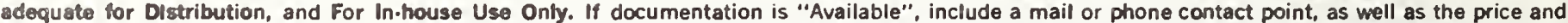
form in which the documentation is available, if possible. If documentation is presently "Inadequate". show the expected availability date.

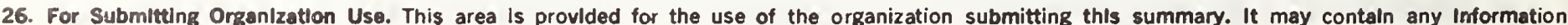
deemed useful for internal operation. 
NBS-114A IREV, 7.73)

\begin{tabular}{|c|c|c|c|}
\hline $\begin{array}{l}\text { U.S. DEPY. OF COMM. } \\
\text { BIBLIOGRAPHIC DATA } \\
\text { SHEET }\end{array}$ & $\begin{array}{l}\text { 1. PUBI.ICATION OR REPORT NO. } \\
\text { NBSIR 78-1509 }\end{array}$ & $\begin{array}{l}\text { 2. Gov't Accession } \\
\text { No. }\end{array}$ & 3. Recipient's Accession No. \\
\hline \multirow{3}{*}{\multicolumn{3}{|c|}{$\begin{array}{l}\text { 4. TITLE AND SUBTITLE } \\
\text { An Algorithm and BASIC Computer Program for Calculating } \\
\text { Simple Coal Gasification Equilibria }\end{array}$}} & \multirow{3}{*}{$\begin{array}{l}\text { 5. Publication Date } \\
\text { 6. Performing Organization Code }\end{array}$} \\
\hline & & & \\
\hline & & & \\
\hline \multicolumn{3}{|l|}{$\begin{array}{l}\text { 7. AUTHOR(S) } \\
\text { William S. Horton }\end{array}$} & 8. Performing Organ. Report No. \\
\hline \multirow{2}{*}{\multicolumn{3}{|c|}{$\begin{array}{l}\text { 9. PERFORMING ORGANIZATION NAME AND ADDRESS } \\
\text { NATIONAL BUREAU OF STANDARDS } \\
\text { DEPARTMENT OF COMMERCE } \\
\text { WASHINGTON, D.C. } 20234\end{array}$}} & 10. Project/Task/Work Unit No. \\
\hline & & & 11. Contract/Grant No. \\
\hline \multirow{3}{*}{\multicolumn{3}{|c|}{ 12. Sponsoring Organization Name and Complete Address (Street, City, State, ZIP) }} & \multirow[t]{2}{*}{$\begin{array}{l}\text { 13. Type of Report \& Period } \\
\text { Covered }\end{array}$} \\
\hline & & & \\
\hline & & & 14. Sponsoring Agency Code \\
\hline
\end{tabular}

15. SUPPLEMENTARY NOTES

16. ABSTRACT (A 200-word or less factual summary of most significant information. If document includes a significant bibliography or literature survey, mention it here.)

Calculation of the equilibrium composition for the gases $\mathrm{CH}_{4}, \mathrm{CO}_{1} \mathrm{CO}_{2}, \mathrm{H}_{2}, \mathrm{and}_{2} \mathrm{H}_{2} \mathrm{O}$ is treated by minimizing the Gibbs energy, G. Minimization is constrained by the conservation of chemical elements. With the use of Lagrangian multipliers, the minimum is found by setting the partial derivatives of $G$ with respect to the amount of each substance equal to zero. The resulting non-linear equations are solved iteratively by the Newton-Raphson method. This algorithm is implemented with an interactive computer program written in the BASIC language and named COLGAS. The aim of this work was to provide people who test materials in coal-gasification-like atmospheres an easy way to obtain the equilibrium composition of their gas mixtures. A knowledge of computer programing is not required in order to use the program. A listing of the program is given and also six sample computer calculations. The phase rule is applied to the $\mathrm{C}-\mathrm{H}-\mathrm{O}$ system and two ternary diagrams are shown illustrating the condensation of solid carbon and liquid water.

17. KEY WORDS (six to twelve entries; alphabetical order; capitalize only the first letter of the first key word unless a proper name; separated by semicolons)

BASIC; carbon; carbon dioxide; carbon monoxide; coal gasification; CoIGAS; hydrogen; interactive computer program; methane; minimization of Gibbs energy; phase rule; simultaneous chemical equilibria; water

\begin{tabular}{|l|l|l|}
\hline 18. AVAILABILITY & XX Unlimited & 19. SECURITY CLASS \\
(THIS REPURT) & 21. NO. OF PAGES \\
$\begin{array}{l}\text { For Official Distribution. Do Not Release to NTIS } \\
\begin{array}{l}\text { Order From Sup. of Doc., U.S. Government Printing Office } \\
\text { Washington, D.C. 20402, SD Cat. No.C13 }\end{array}\end{array}$ & $\begin{array}{l}\text { 20. SECURITY CLASS } \\
\text { (THIS PAGE) }\end{array}$ \\
$\begin{array}{l}\text { Order From National Technical Information Service (NTIS) } \\
\text { Springfield, Virginia 22151 }\end{array}$ & 22. Price \\
\hline
\end{tabular}



